\title{
Effects of long-period processing on structural collapse predictions
}

Earthquake Spectra 202I, Vol. 37(I) 204-234

(C) The Author(s) 2020

Article reuse guidelines: sagepub.com/journals-permissions DOI: I0.II77/8755293020936699

journals.sagepub.com/home/eqs

(SAGE

\author{
Kenny Buyco, M.EERI', Becky Roh ${ }^{2}$ and \\ Thomas H. Heaton, M.EERI ${ }^{2}$
}

\begin{abstract}
We investigate the extent to which applying high-pass filters to ground motion records affects the collapse capacity of building models. We consider 26 ground motion records from seven large earthquakes and high-pass filter them with corner periods, $T_{c}$, ranging from 10 to $60 \mathrm{~s}$. We perform incremental dynamic analysis on 9, 20-, and 55-story steel moment-frame building models with fundamental periods of I.88, 3.50, and 6.10 seconds, respectively. Even though filters with $T_{c} \geqslant 20 \mathrm{~s}$ have a minimal effect on the collapse capacities of the building models, we find that for a few motions, collapse capacities can increase by more than $50 \%$, if $T_{c}=10$ or $15 \mathrm{~s}$, even for the 9-story models. We find that the collapse capacities with respect to raw, uncorrected records are generally similar to those of the tilt-corrected versions, indicating that removing long-period noise with high-pass filters can make collapse predictions less accurate, if $T_{c}<20 \mathrm{~s}$.
\end{abstract}

\section{Keywords \\ Collapse, engineering seismology, strong-motion records, ground motion processing, steel moment-frame}

Date received: 23 April 2020; accepted: 30 April 2020

\footnotetext{
'Arup, San Francisco, CA, USA

${ }^{2}$ California Institute of Technology, Pasadena, CA, USA

Corresponding author:

Kenny Buyco, Arup, 560 Mission St., San Francisco, CA 94105, USA.

Email: kenny.buyco@arup.com
} 


\section{Introduction}

The NGA-West2 database (Ancheta et al., 2014) of recorded and processed ground motions was developed to calculate ground motion prediction equations (GMPEs) for a variety of ground motion intensity measures. Although not explicitly created for structural analysis, the NGA-West2 database has also been used by engineers as a source of input ground motions for response history analysis of structural models. To remove long-period noise from raw recorded ground motions, each ground motion in the NGA-West2 database is high-pass filtered with a record-specific corner period $\left(T_{c}\right)$. Long-period noise can include a tilt of the instrument during shaking, which introduces a static acceleration offset into the record that is not physically present in the true ground motion. For some applications (e.g. calculation of GMPEs for peak ground acceleration (PGA)), these high-pass filters do not affect the results of analysis when using ground motions from the NGA-West2 database. However, in other cases (e.g. estimating the collapse capacity of a building), the removal of long-period components from raw ground motions may have an impact.

For a large earthquake, near-fault ground displacement is predominantly described by the static offset, which can be as large as $10 \mathrm{~m}$ (Ma et al., 1999). However, in the displacement time series of ground motion records in the NGA-West2 database, there is no recognition of static offsets or permanent displacement offsets (Kamai and Abrahamson, 2015). The explanation for this lies in the record processing methodology used by NGA-West2, which consists of a series of steps that include demeaning the raw record, correcting unrealistic trends, and acausal high-pass filtering (Ancheta et al., 2014).

Applying high-pass filters to remove long-period noise from the raw record can also have unintended consequences with regards to the predicting structural response. For example, Boore and Akkar (2003) and Burks and Baker (2014) showed that high-pass acausal filters with corner periods that are too low can affect the inelastic displacement and collapse capacity, respectively, of nonlinear single-degree-of-freedom (SDOF) systems. To reflect the concerns associated with high-pass filters, the NGA-West 2 flatfile reports a maximum usable period for each ground motion component equal to $80 \%$ of the corner period. When selecting input ground motion records for the design of new buildings, it has been common to only select records for which the maximum usable period is greater than $1.5 T_{1}$, where $T_{1}$ is the fundamental period of the structure of interest (Haselton, 2009). In some cases, ensuring that periods up to $1.5 T_{1}$ are preserved in the ground motion is sufficient to accurately assess its potential to cause collapse in a building model. However, some ground motions can have a substantial portion of their spectral content at long periods beyond $1.5 T_{1}$, particularly those recorded in large-magnitude events. It should be noted that ASCE 7-16 (American Society of Civil Engineers (ASCE), 2016) requires ground motions selected for nonlinear time history analysis to match the target spectrum at periods up to $2 T_{1}$, instead of $1.5 T_{1}$ as in previous versions of ASCE 7.

In this study, we select 26 records from large-magnitude events and process them in a manner that preserves the static offset. We also apply high-pass filters to these ground motion records to evaluate the effects of filtering. We then perform incremental dynamic analysis (IDA) with each of these processed ground motions on models of three mid- to high-rise steel moment-frame building models $(9,20$, and 55 stories) to evaluate the collapse capacity of each model to each ground motion and how this is affected by processing the records. Particular attention is paid to seven ground motions that represent particularly strong shaking. 


\section{Ground motion processing}

\section{Ground tilt}

High-pass filtering allows for instrument correction and noise reduction, which can manifest themselves at long periods. For example, an unrealistic acceleration offset is found in many of the horizontal raw records from large earthquakes. This acceleration offset recorded by the instrument can occur due to ground tilt, which produces a horizontal acceleration in the instrument proportional to gravity. This is shown in Equation 1:

$$
A_{x}(t)=\ddot{u}_{x}(t)+g \cdot \sin \theta_{x}(t) \approx \ddot{u}_{x}(t)+g \cdot \theta_{x}(t),
$$

where $A_{x}(t)$ is a horizontal component of the recorded acceleration, $\theta_{x}(t)$ is the tilt of the site in the $x$-direction, $g$ is gravitational acceleration, and $\ddot{u}_{x}(t)$ is the "true" horizontal acceleration. In most cases, $\theta_{x}(t)$ is quite small, justifying the small-angle approximations made in Equation 1.

In this study, we assume the ground tilt occurs instantaneously (Yamada et al., 2007), so that:

$$
\theta_{x}(t)=\bar{\theta}_{x} H\left(t-t_{0}\right)
$$

where $\bar{\theta}_{x}$ is the final tilt in the $x$-direction, $H(t)$ is the Heaviside step function, and $t_{0}$ is the time at which the tilt occurs. As such, if $\bar{\theta}_{x}$ and $t_{0}$ are known for an uncorrected acceleration record, the tilt $\theta_{x}(t)$ can be removed to create a "tilt-corrected" record.

Given this form for $\theta_{x}(t)$, the acceleration tilt $g \cdot \theta_{x}(t)$ is a mostly long-period phenomenon, so its effects can also be removed by applying a high-pass filter to the record. Even though tilt-correcting and high-pass filtering both remove the tilt effects, the resulting displacement time histories are quite different. To investigate the effects of these different processing methods, we assemble near-source ground motion records from large events and process them in different ways, leading to three classes of processed ground motions: (1) demeaned raw, uncorrected records, where available; (2) tilt-corrected records; and (3) high-pass filtered records, with the $T_{c}$ ranging from 10 to $60 \mathrm{~s}$.

It is important to note that, while instantaneous ground tilt is assumed for simplicity, removing an instantaneous ground tilt is not the only method for generating a tiltcorrected record. For example, Graizer (2006) produces tilt-corrected records by modeling the dynamic instrumental response as damped sinusoidal motion and removing both this and an acceleration step from the raw record. One could argue that the tilt-corrected records generated for this study are not necessarily the best representation of the "true" ground motion (e.g. dynamic instrumental response could be incorporated), but an investigation into how different tilt-correction procedures could affect structural response is outside the scope of this study, as the focus is on evaluating different methods of high-pass filtering. However, the question of how different tilt-correction procedures affect structural response is an interesting one, and could be explored further in a future study.

The following sections describe the considered ground motions and detail the tiltcorrection and filtering procedures. 


\section{Ground motion records}

The ground motion records we use in this study consist of ground motions from seven large earthquakes:

i. $\quad 2016$ M7.8 Kaikōura, New Zealand

ii. 2016 M7.0 Kumamoto, Japan

iii. 2015 M7.8 Gorkha, Nepal

iv. 2008 M7.9 Wenchuan, China

v. 2002 M7.9 Denali, Alaska

vi. 1999 M7.6 Chi-Chi, Taiwan

vii. 1992 M7.3 Landers, California

From these earthquakes, records from 26 stations are collected. We focus on the horizontal components for simplicity. The chosen records are from stations in regions with strong shaking and large static offsets in the displacement.

For earthquakes (i)-(iv), raw, uncorrected acceleration records are available from different strong-motion databases. The following databases are used to collect the raw data: GeoNet for the Kaikōura earthquake; K-NET, KiK-net, and the Japan Meteorological Agency (JMA) for the Kumamoto earthquake; the California Strong-Motion Instrument Program (CSMIP) for the Gorkha earthquake; and the National Strong-Motion Observation Network System (NSMONS) of China for the Wenchuan earthquake.

For earthquakes (v)-(vii), raw acceleration records (corrected or uncorrected) are not available. However, other researchers have processed records using procedures that preserve the static offset and made them accessible for the Chi-Chi (Boore, 2001) and Landers (Chen, 1995) earthquakes. For the Denali earthquake, Ellsworth et al. (2004) provide published ground displacements with the static offsets preserved, which we digitize to extract the time series. Records from earthquakes (v)-(vii) are also available in the NGA-West2 database (Ancheta et al., 2014) and were processed using the NGA-West 2 methodology, which removes static offsets but preserves the "short"-period (i.e. shorter than $T_{c}$ ) components. High-pass filter corner periods for these records were chosen on a record-by-record basis for the NGA-West 2 project with $T_{c}$ as low as $5 \mathrm{~s}$.

For earthquakes (v)-(vii), we require broadband records that contain both the "short"period components preserved in the NGA-West 2 records and the static offsets preserved by the citations referenced in the preceding paragraph. Therefore, for each record from earthquakes (v)-(vii), we combine its NGA-West2 record with the record containing static offsets using the procedure described in Chapter 7 of the work of Yang (2009) to generate a suitable broadband record. The stated purpose of the procedure is to combine inertial seismic records and high-sample rate global positioning system (GPS) records to generate broadband displacement records, so it is applicable for our purposes. The reader is referred to Yang (2009) for a more thorough description of this procedure for generating broadband records. It should be noted that the only subjective parameter required for this procedure is the period used to separate "short" periods from "long" periods. For the records generated in this article, this period is chosen as the period at which the Fourier spectra of the two combined records intersect. It is noted by Yang (2009) that the results are not generally sensitive to this parameter. 


\section{Processing methodology}

For each horizontal ground motion record component from earthquakes (i)-(iv), for which raw, uncorrected records are available, we produce three types of processed records using the procedures outlined in Figure 1: a "raw" record, a "tilt-corrected" record, and several "filtered" records (with filters with different $T_{c}$ ). Raw, uncorrected records are not available from earthquakes (v)-(vii), so we assume the procedure for combining NGAWest 2 records with records containing static offsets described in the previous section produces broadband records that are suitable tilt-corrected records. From these tilt-corrected records from earthquakes (v)-(vii), filtered records are generated in the same manner as those from earthquakes (i)-(iv). The remainder of this section describes the processing methodology for the three types of processed records.

To create a suitable "raw" record for structural analysis, we remove the mean from the uncorrected acceleration record, so that any static offset present in the uncorrected record before shaking begins does not dominate structural response. We remove the mean from the entire record instead of the pre-event (before $p$-wave arrival) mean to be as naive as possible when creating the raw record.

The steps to produce the "tilt-corrected" record are plotted in greater detail in Figure 2. First, we remove the pre-event mean (Figure 2a) from the uncorrected acceleration record. We remove the pre-event mean instead of the mean from the entire record because the latter is contaminated by tilt effects during shaking. Then from the velocity record we identify $t_{0}$ by inspection, which is the time at which we assume the tilt occurs (Equation 2). We correct the tilt effects (Figure $2 \mathrm{~b}$ ) by removing a linear trend, $v_{\text {trend }}(t)$, in the velocity record. We calculate $v_{\text {trend }}(t)$ by applying to the velocity record a least-squares regression (Yamada et al., 2007) of the form shown in Equation 3:

$$
v_{\text {trend }}(t)=C_{1}\left(t-t_{0}\right) \cdot H\left(t-t_{0}\right)+C_{2}
$$

where $C_{1}$ and $C_{2}$ are the least-squares regression coefficients. Note that $C_{1}=g \cdot \sin \bar{\theta}_{x}$ represents the horizontal acceleration removed from the record and attributed to tilt. Removal of $v_{\text {trend }}(t)$ from the velocity record typically results in a displacement time series that is stable and that preserves the static offset.

The value of $t_{0}$ will affect the static offset in the displacement record, so if observations of the static offsets are available for a record, we iteratively select $t_{0}$ until our calculated static offset approximately matches the observed offset (Figure 2c). Observed static offsets are available from the works of Hamling et al. (2017) for the Kaikoura earthquake, Asano and Tomotaka (2016) for the Kumamoto earthquake, Galetzka et al. (2015) for the Gorkha earthquake, Lu et al. (2010) for the Wenchuan earthquake, Ellsworth et al. (2004) for the Denali earthquake, Boore (2001) for the Chi-Chi earthquake, and Chen (1995) for the Landers earthquake. If observations of the static offsets are not available for a particular record, we consider the choice of $t_{0}$ acceptable if it results in a stable displacement time series. This was true for eight of the 26 considered records, and these records are indicated in Table 1 later in this article. For each record, once a choice of $t_{0}$ is deemed acceptable, we consider the resulting processed record the "tilt-corrected" record. It should be noted that the choice of $t_{0}$ is not necessarily unique, especially for the records for which observed static offsets are not available. This has been observed by previous researchers (e.g. Boore and Bommer, 2005). The effects of the choice of $t_{0}$ on structural response are not 


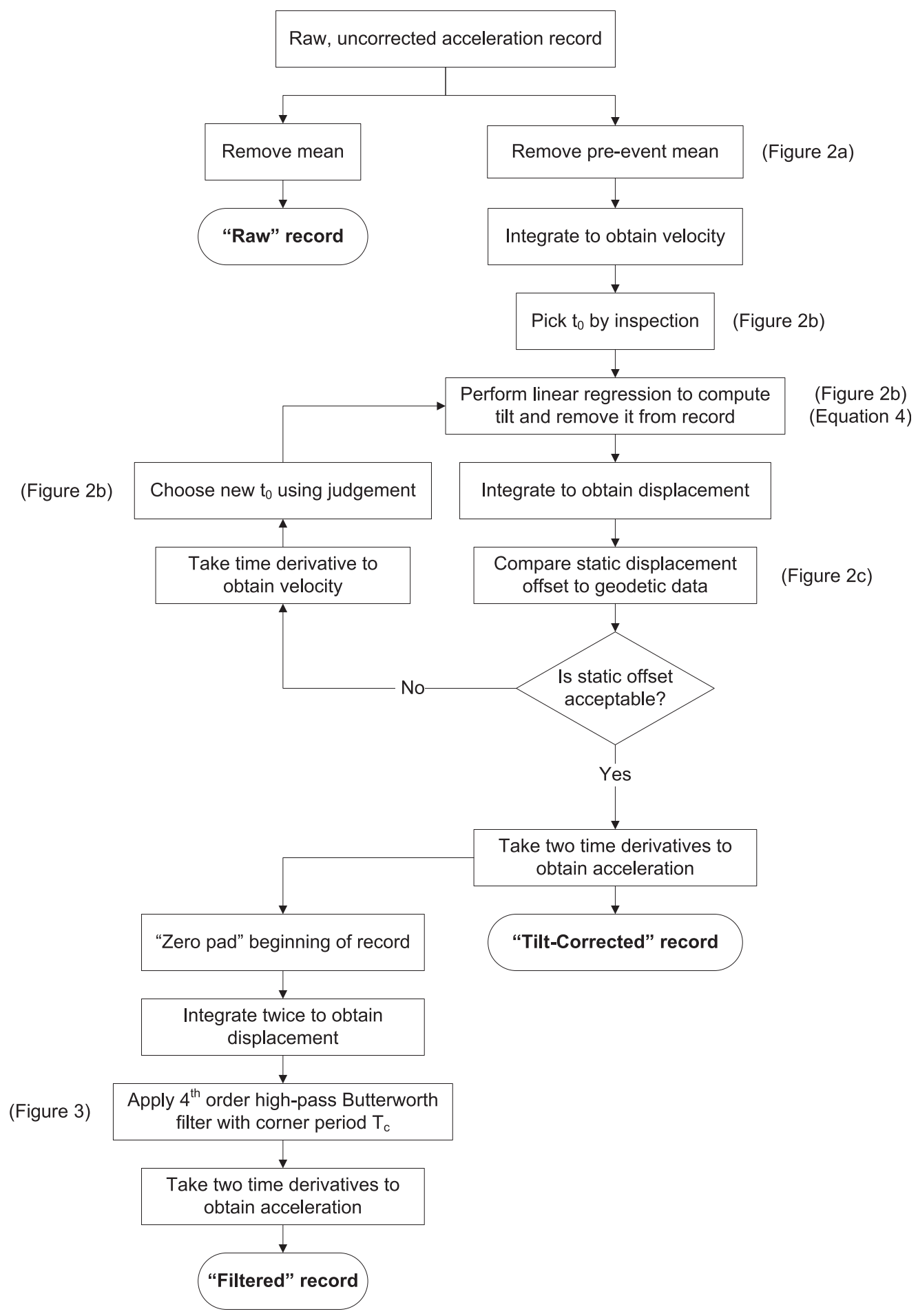

Figure I. Flowchart detailing the procedure for obtaining raw, tilt-corrected, and filtered records from those recorded in earthquakes (i)-(iv), for which raw, uncorrected records are available. 


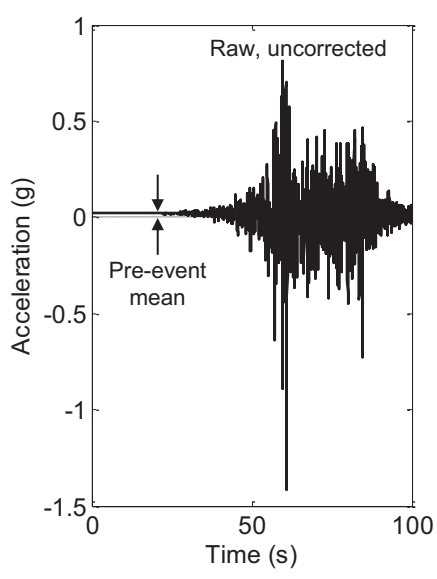

(a)

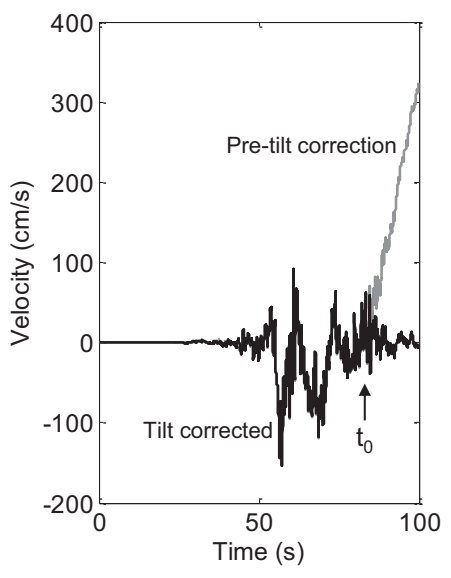

(b)

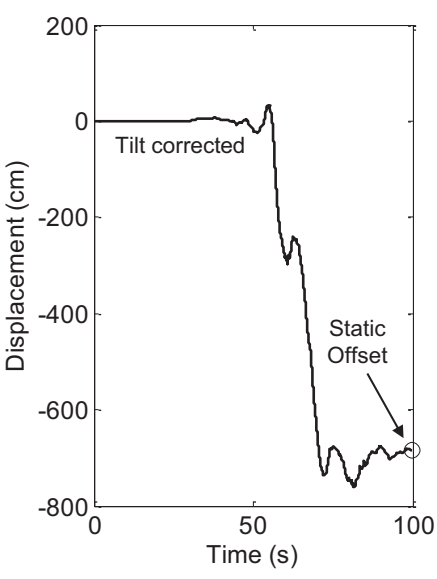

(c)

Figure 2. Steps for obtaining tilt-corrected record from raw, uncorrected record. In this example, the 2016 M7.8 Kaikoura KEKS NS record is processed. (a) Pre-event mean is removed from acceleration record, (b) linear trend is removed from velocity record and (c) final static offset in displacement record is checked to ensure stability and, if available, agree with geodetic data.

considered in this study, but this could be investigated in a future study that considers a variety of tilt-correction procedures and implementations.

After a horizontal component of a ground motion record is tilt-corrected, we can calculate its tilt angle $\bar{\theta}_{x}$ according to Equation 4:

$$
\bar{\theta}_{x}=\sin ^{-1}\left(\frac{C_{1}}{g}\right)
$$

We find the tilt is always less than $3^{\circ}$ and usually less than $1^{\circ}$ for the horizontal ground motions. Note that a tilt angle of one degree corresponds to $0.0175 \mathrm{~g}$ of horizontal acceleration.

To generate filtered records from the tilt-corrected records, we apply acausal and causal fourth-order Butterworth high-pass filters. The NGA-West 2 project uses acausal high-pass Butterworth filters (Ancheta et al., 2014), which is a change from the NGA-West1 project, for which causal Butterworth filtered records were preferred. Acausal filters were used in the NGA-West 2 project because causal filters introduce phase distortions and have been shown to affect measurements of spectral accelerations (Boore and Akkar, 2003). We implement acausal filters by first filtering the record in the forward time direction with a causal filter and then convolving the filtered record with a time-reversed copy of the same causal filter to remove the phase shifts. The acausal filter preserves the timing of the peakto-peak values, but removes the static offset and adds a precursory motion, usually leading to a reduction in the peak displacement of the record.

Butterworth filters are the most common type of filter used in engineering seismology because of their relatively flat passbands in the frequency domain. Equation 5 shows the magnitude of the gain of a $n$-order causal high-pass Butterworth filter, $\left|B_{n}^{h p}(\omega)\right|$, as a function of angular frequency, $\omega$ : 
Table I. Details of every considered ground motion record. Reported values of PGA, peak ground velocity (PGV), peak ground displacement (PGD), and tilt are the maximum of the two recorded horizontal directions and are calculated from the tilt-corrected records. The reported $T_{c}$ values correspond to high-pass filter corner periods for the NGA-West2 records, where applicable. The tilt angle cannot be calculated for earthquakes for which raw, uncorrected records are not available

\begin{tabular}{|c|c|c|c|c|c|c|c|c|}
\hline Earthquake & $M$ & Station & $R_{\mathrm{JB}}$ & PGA (g) & PGV $(\mathrm{cm} / \mathrm{s})$ & PGD $(\mathrm{cm})$ & Tilt $\left({ }^{\circ}\right)$ & $T_{c}(\mathrm{~s})$ \\
\hline 2016 Kaikōura & 7.8 & $\begin{array}{l}\text { CULC } \\
\text { KEKS } \\
\text { KIKS } \\
\text { WDFS } \\
\text { WIGC } \\
\text { WTMC }\end{array}$ & $\begin{array}{l}15.6 \\
3.0 \\
0.7 \\
8.5 \\
18.0^{\mathrm{b}} \\
0.7\end{array}$ & $\begin{array}{l}0.27 \\
1.97 \\
0.51 \\
2.51 \\
0.75 \\
1.12\end{array}$ & $\begin{array}{l}29 \\
269 \\
160 \\
210 \\
64 \\
117\end{array}$ & $\begin{array}{l}75^{\mathrm{a}} \\
867 \\
304 \\
816 \\
52^{\mathrm{a}} \\
284^{\mathrm{a}}\end{array}$ & $\begin{array}{l}0.62 \\
1.54 \\
1.83 \\
1.23 \\
2.73 \\
0.01\end{array}$ & $\begin{array}{l}- \\
- \\
- \\
- \\
- \\
-\end{array}$ \\
\hline 2016 Kumamoto & 7.0 & $\begin{array}{l}93048 \\
9305 \mathrm{I} \\
\text { KMM00I } \\
\text { KMM004 } \\
\text { KMM005 } \\
\text { KMM007 } \\
\text { KMM009 } \\
\text { KMMHI6 } \\
\text { OIT009 }\end{array}$ & $\begin{array}{l}0.6 \\
0.5 \\
5.0^{\mathrm{b}} \\
3.9^{\mathrm{b}} \\
5.6 \\
3.5^{\mathrm{b}} \\
2.2^{\mathrm{b}} \\
0.5 \\
7.8^{\mathrm{b}}\end{array}$ & $\begin{array}{l}0.79 \\
0.84 \\
0.22 \\
0.35 \\
0.54 \\
0.43 \\
0.79 \\
1.18 \\
0.73\end{array}$ & $\begin{array}{l}264 \\
178 \\
39 \\
82 \\
69 \\
44 \\
38 \\
142 \\
78\end{array}$ & $\begin{array}{l}186 \\
105 \\
45^{\mathrm{a}} \\
74^{\mathrm{a}} \\
115 \\
40^{\mathrm{a}} \\
41^{\mathrm{a}} \\
228 \\
102^{\mathrm{a}}\end{array}$ & $\begin{array}{l}0.58 \\
0.48 \\
0.58 \\
0.12 \\
0.55 \\
0.27 \\
0.19 \\
0.08 \\
0.11\end{array}$ & $\begin{array}{l}- \\
- \\
- \\
- \\
- \\
- \\
- \\
- \\
-\end{array}$ \\
\hline 2015 Gorkha & 7.8 & KATNP & 0.1 & 0.16 & 112 & 246 & 0.02 & - \\
\hline 2008 Wenchuan & 7.9 & $\begin{array}{l}\text { AXT } \\
\text { MZQ } \\
\text { SFB }\end{array}$ & $\begin{array}{l}9.8 \\
0.8 \\
4.8\end{array}$ & $\begin{array}{l}0.29 \\
0.82 \\
0.58\end{array}$ & $\begin{array}{l}31 \\
136 \\
81\end{array}$ & $\begin{array}{l}105 \\
213 \\
318\end{array}$ & $\begin{array}{l}0.04 \\
0.07 \\
2.04\end{array}$ & $\begin{array}{l}- \\
- \\
-\end{array}$ \\
\hline 2002 Denali & 7.9 & PSIO $0^{c}$ & 3.0 & 0.33 & 137 & 302 & - & 10.0 \\
\hline 1999 Chi-Chi & 7.6 & $\begin{array}{l}\text { TCU052 } \\
\text { TCU065 } \\
\text { TCU067 } \\
\text { TCU068 } \\
\text { TCU084 }\end{array}$ & $\begin{array}{l}1.8 \\
2.5 \\
1.1 \\
3.0 \\
11.4\end{array}$ & $\begin{array}{l}0.45 \\
0.79 \\
0.50 \\
0.51 \\
1.00\end{array}$ & $\begin{array}{l}225 \\
135 \\
100 \\
298 \\
118\end{array}$ & $\begin{array}{l}740 \\
198 \\
191 \\
885 \\
251\end{array}$ & $\begin{array}{l}- \\
- \\
- \\
- \\
-\end{array}$ & $\begin{array}{l}25.0 \\
d \\
e \\
e \\
f\end{array}$ \\
\hline 1992 Landers & 7.3 & $\operatorname{LUC}^{c}$ & 2.0 & 0.76 & 146 & 263 & - & $g$ \\
\hline
\end{tabular}

${ }^{a}$ Record did not contain a published static offset.

${ }^{b}$ Epicentral distance is reported because $R_{J B}$ is not available.

${ }^{\mathrm{C}}$ Two horizontal directions are oriented parallel and normal to the ruptured fault.

${ }^{d}$ For NGA-West2 record, different $T_{c}$ in each direction: 33.3 and $16.7 \mathrm{~s}$.

e For NGA-West2 record, different $T_{c}$ in each direction: 50.0 and $33.3 \mathrm{~s}$.

${ }^{f}$ For NGA-West2 record, different $T_{c}$ in each direction: 10.0 and $5.0 \mathrm{~s}$.

${ }^{g}$ For NGA-West2 record, no high-pass filter.

$$
\left|B_{n}^{h p}(\omega)\right|=\frac{1}{\sqrt{1+\left(\frac{\omega_{c}}{\omega}\right)^{2 n}}}
$$

where $\omega_{c}=2 \pi / T_{c}$ is the corner frequency and $T_{c}$ is the corner period. In this study, we apply filters with $n=4$, which results in the frequency response: 


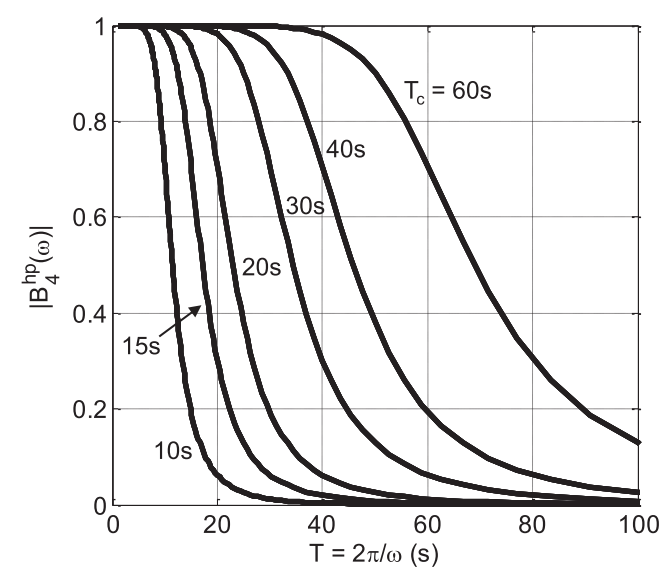

(a)

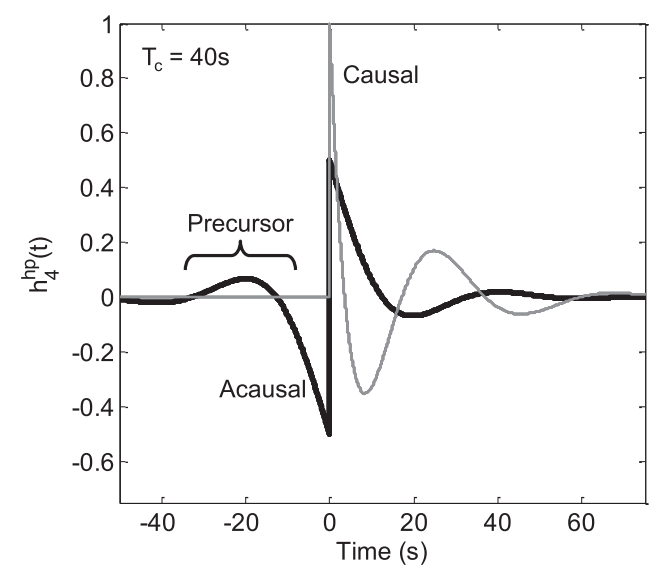

(b)

Figure 3. (a) The gain, $\left|B_{h p}^{4}(\omega)\right|$, of fourth-order high-pass Butterworth filters with $T_{c}=10,15,20,30$, 40 , and $60 \mathrm{~s}$. (b) The impulse response functions corresponding to acausal and causal fourth-order highpass Butterworth filters with $T_{c}=40 \mathrm{~s}$.

$$
B_{4}^{h p}(\omega)=\frac{1}{\left(-\left(\frac{\omega_{c}}{\omega}\right)^{2}+i \alpha\left(\frac{\omega_{c}}{\omega}\right)+1\right)\left(-\left(\frac{\omega_{c}}{\omega}\right)^{2}+i \beta\left(\frac{\omega_{c}}{\omega}\right)+1\right)}
$$

where

$$
\alpha, \beta=\sqrt{1+\frac{1}{\sqrt{2}} \pm \sqrt{1-\frac{1}{\sqrt{2}}}}
$$

The corresponding impulse response of a 4-order causal high-pass Butterworth filter, $h_{4}^{h p}(t)$, can be calculated as:

$$
h_{4}^{h p}(t)=\mathrm{F}^{-1}\left\{B_{4}^{h p}(\omega)\right\}
$$

where $\mathrm{F}^{-1}$ is the inverse Fourier transform. Plots of $\left|B_{h p}^{4}(\omega)\right|$ and $h_{4}^{h p}(t)$ in Equations 5 and 8 are shown in Figure 3. In Figure 3a, $\left|B_{h p}^{4}(\omega)\right|$ is plotted for $T_{c}=10,15,20,30,40$, and $60 \mathrm{~s}$. In Figure $3 \mathrm{~b}, h_{4}^{h p}(t)$ is plotted for $B_{h p}^{4}(\omega)$ calculated with $T_{c}=40 \mathrm{~s}$. Also shown in Figure $3 b$ is the impulse response for a corresponding acausal filter, which is calculated by convolving the causal impulse response, $h_{4}^{h p}(t)$, with a time-reversed copy of itself. The acausal impulse response displays a significant precursory motion that occurs before the impulse.

To produce the filtered records we use in this study, we begin with the tilt-corrected acceleration record. We then apply points of zero acceleration to the beginning of the record to satisfy zero initial conditions before filtering (Boore, 2005). The "padded zeroes" are not removed after filtering. After zero-padding, we apply a Butterworth filter to the displacement record. For each record, we generate 12 filtered records by filtering it with a causal and an acausal fourth-order high-pass Butterworth filter with $T_{c}$ of 10, 15, 20, 30, 


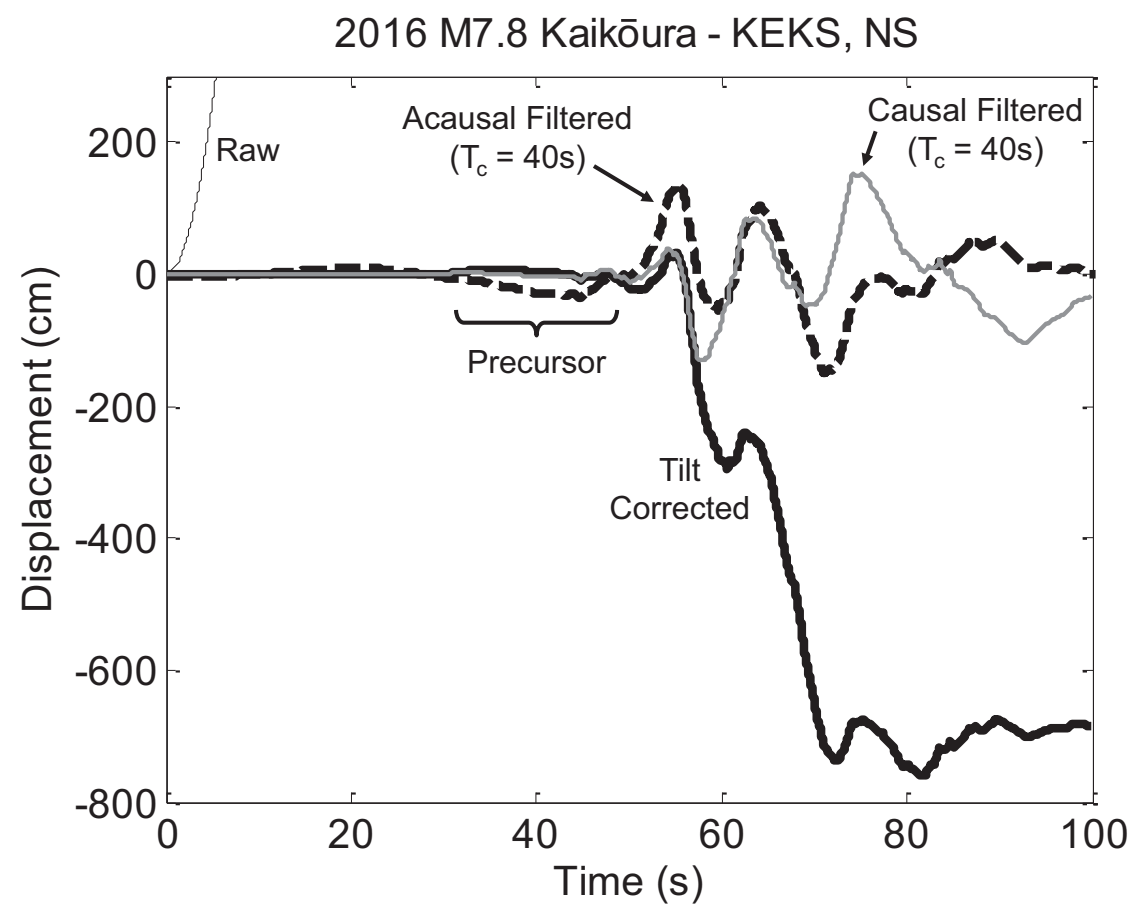

Figure 4. Example of raw, tilt-corrected, and filtered record. In this example, the 2016 M7.8 Kaikoura KEKS NS record is processed.

40 , and $60 \mathrm{~s}$. For reference, in the NGA-West 2 database, $T_{c}=10 \mathrm{~s}$ is used most frequently for $M>6.0$ and $R_{J B}<20 \mathrm{~km}$ and $T_{c}=33.33 \mathrm{~s}$ is used most frequently for $M>7.0$ and $R_{J B}<20 \mathrm{~km}$ (Ancheta et al., 2014; Kamai and Abrahamson, 2015).

As an example, the raw and tilt-corrected displacement records from the KEKS station in the 2016 M7.8 Kaikōura earthquake in the NS direction are shown in Figure 4 along with the corresponding filtered records using acausal and causal filters with $T_{c}=40 \mathrm{~s}$. The raw displacement record immediately increases to unrealistic values, because the raw acceleration record has a small pre-event constant offset that integrates to a quadratic offset in the corresponding displacement record.

Like previous researchers (e.g. Boore and Akkar, 2003; Boore and Bommer, 2005), we find that causal filters dramatically alter structural responses because they introduce phase distortions in the ground motion record. This is consistent throughout all ground motions and building models. As such, for all subsequent analysis and discussion, all "filtered" ground motions are processed with acausal high-pass filters. We will no longer consider causal high-pass filters. It should be noted that this implies that the significant precursor created by filtering a record with an acausal high-pass filter does not have much of an effect on structural response. These observations are discussed further by Buyco (2018).

\section{Processed ground motions}

Information for each tilt-corrected ground motion record is shown in Table 1. For each record, there are two orthogonal horizontal directions. With two exceptions, the two 
horizontal components of every record are oriented with no regard for fault geometry (e.g. north-south and east-west directions). The two exceptions are the 1992 M7.3 Landers LUC and 2002 M7.9 Denali PS10 records, both of which have one fault-parallel (FP) horizontal component and one fault-normal (FN) horizontal component. For the remainder of this article, a single component of a ground motion record will be referred to by the earthquake name, station name, and component (e.g. Kaikōura KEKS NS).

To demonstrate the differences between raw, tilt-corrected, filtered, and NGA-West2 records, Figure 5 shows the processed velocity and displacement time series for the Kumamoto 93048 EW record, the Landers LUC FN record, and the Chi-Chi TCU068 NS record. The filtered records shown in Figure 5 have $T_{c}=10 \mathrm{~s}$. The NGA-West2 versions of the Landers LUC FN and Chi-Chi TCU068 NS records are taken from the NGA-West 2 database. For the Kumamoto record, a raw record is available and the tilt effects are clear in both the velocity and displacement time series. Acceleration time series are not shown because the effects of long-period processing on the acceleration records are imperceptible to the naked eye.

The differences between the tilt-corrected records and the filtered and NGA-West2 records are most apparent in the displacement time series. Compared with the tilt-corrected records, the filtered and NGA-West 2 displacement time series contain precursors, as would be expected from acausal filtered records. Furthermore, the peak displacements are always smaller in the filtered and NGA-West2 records than in the tilt-corrected records. The effects of filtering are not as obvious in the velocity time series except in the Chi-Chi TCU068 NS record, for which the filtered record with $T_{c}=10 \mathrm{~s}$ has a significantly lower peak velocity than the other records.

To further demonstrate the effects of the filters on the velocity of the records, Table 2 shows the PGV of one component of a record from each earthquake and compares the tiltcorrected PGV with the filtered PGV with various $T_{c}$. The records shown in Table 2 are those that achieve the largest PGV from each earthquake. Where available, the PGV from the record in the NGA-West 2 database is shown for comparison.

In every case, the PGV of the filtered record is less than that of the tilt-corrected record. For $T_{c}=40 \mathrm{~s}$, the PGV is usually within about $10 \%$ of the tilt-corrected PGV. In the most extreme case, for the Chi-Chi TCU068 NS component, the $T_{c}=10 \mathrm{~s}$ filtered record has a PGV that is about $50 \%$ of the tilt-corrected PGV. The NGA-West 2 records also have lower PGV than the tilt-corrected records. It should not be surprising that the discrepancy between the NGA-West2 PGV and the tilt-corrected PGV depends on the reported $T_{c}$ from the NGA-West 2 flatfile. Interestingly, the PGV of the tilt-corrected Landers LUC FN record is $7 \%$ larger than the corresponding NGA-West 2 record even though no highpass filter was applied to produce the NGA-West 2 record. Instead, the discrepancy can be explained by the removal of a sixth-order polynomial from the displacement record prior to filtering in the NGA-West 2 processing procedure (Ancheta et al., 2014). So even though the Landers LUC FN NGA-West2 record was not high-pass filtered, removing a sixthorder polynomial from the record removed enough of the signal for the PGV to be reduced by $7 \%$.

The effects of long-period processing on the response spectra of a few records can be seen later in this article in Figures $8 \mathrm{~b}$ and 14, where the impacts on structural response are discussed in detail. 


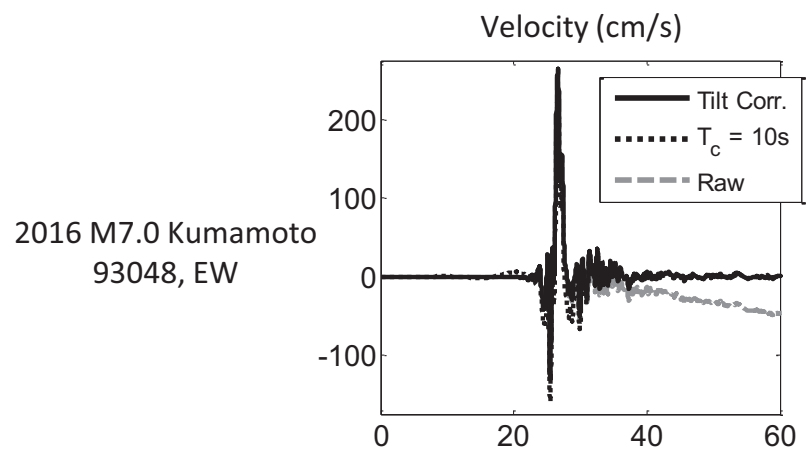

(a)

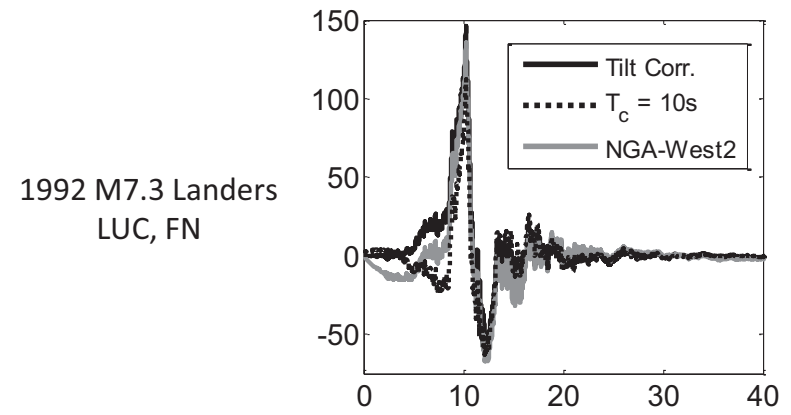

(c)

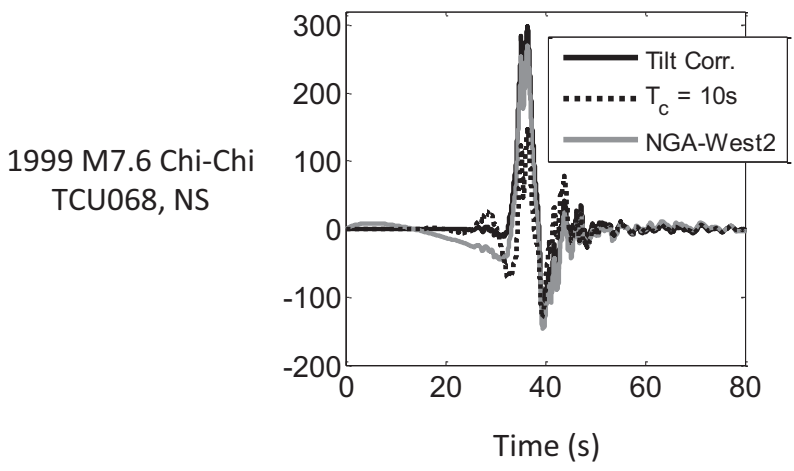

(e)

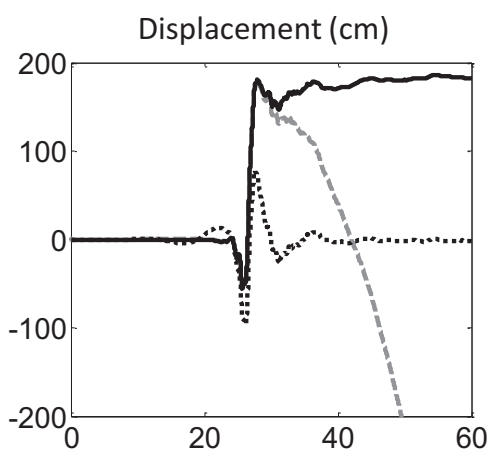

(b)

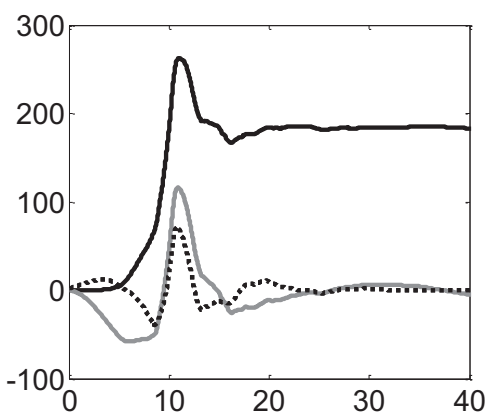

(d)

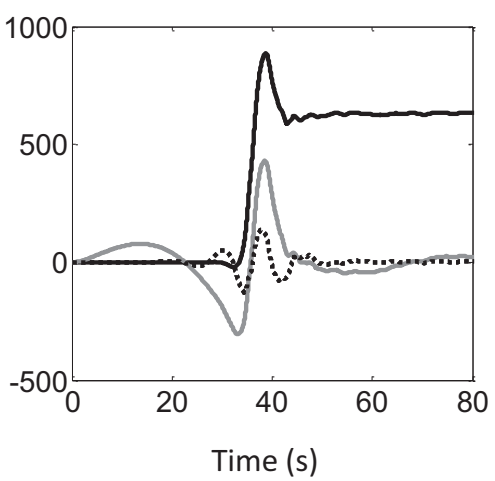

(f)

Figure 5. Examples of velocity and displacement series processed using different techniques. The acausal filtered records are filtered with $T_{c}=10$ s. (a, b) 2016 M7.0 Kumamoto 93048, EW; (c, d) 1992 M7.3 Landers LUC, FN; (e, f) 1999 M7.6 Chi-Chi TCU068, NS.

\section{Incremental dynamic analysis}

\section{Building models}

To quantify the effects of different ground motion processing techniques on structural response, we perform IDA with these ground motions on several different building models. We consider six steel moment-frame models. The six steel moment-frame models are developed from three designs of steel moment-frame buildings with heights of 9, 20, and 
Table 2. PGV of tilt-corrected and filtered records for ground motion records that have the highest PGV from each considered earthquake

\begin{tabular}{llllllll}
\hline Earthquake & Station & \multirow{2}{*}{ Component } & \multicolumn{2}{l}{ PGV $(\mathrm{cm} / \mathrm{s})$} & \\
\cline { 4 - 8 } & & & Tilt corr. & $T_{c}=10 \mathrm{~s}$ & $T_{c}=20 \mathrm{~s}$ & $T_{c}=40 \mathrm{~s}$ & NGA-West2 \\
\hline Kaikoura & KEKS & EW & 269 & 213 & 232 & 235 & - \\
Kumamoto & 93048 & EW & 264 & 230 & 247 & 255 & - \\
Gorkha & KATNP & EW & 112 & 98 & 103 & 108 & - \\
Wenchuan & MZQ & EW & 136 & 89 & 117 & 129 & - \\
Denali & PSI0 & FP & 137 & 104 & 114 & 124 & $103^{\mathrm{a}}$ \\
Chi-Chi & TCU068 & NS & 298 & 147 & 230 & 265 & $269^{\mathrm{b}}$ \\
Landers & LUC & FN & 146 & 113 & 128 & 137 & $136^{\mathrm{c}}$ \\
\hline
\end{tabular}

${ }^{\mathrm{a}} T_{c}=10.0 \mathrm{~s}$ and maximum usable period is $7.7 \mathrm{~s}$.

${ }^{\mathrm{b}} T_{c}=50.0 \mathrm{~s}$ and maximum usable period is $40.0 \mathrm{~s}$.

${ }^{\mathrm{C}}$ No high-pass filter.

55 stories. For each design, two models are created, one with "perfect" (P) moment connections and one with pre-Northridge "brittle" (B) moment connections, for a total of six models.

The 9- and 20-story building designs were developed for the SAC Joint Venture by Gupta and Krawinkler (1999) and designed according to the 1994 Uniform Building Code (UBC). The 55-story building was also designed according to the 1994 UBC with a procedure and floor plan similar to the high-rise presented in Chapter 8 of Dizon (2016). The 55-story building was designed by Dizon (2016) and was generously provided to the authors of this article for analysis. The section properties of the 55-story building are available in Appendix A of Buyco (2018). The above-ground heights of the of the 9-, 20-, and 55-story designs are $37.2 \mathrm{~m}$ (122 feet), $80.8 \mathrm{~m}$ (265 feet), and $220.0 \mathrm{~m}$ (722 feet), respectively.

We create two-dimensional finite element models of each building using Frame-2d, a finite element software that is specifically designed to calculate the seismic response of steel moment-frame buildings using fiber elements to model the behavior of beams and columns. The cross-section of each element is divided into fibers that have hysteretic axial stress-strain relationships, equipped with a yield plateau and strain-hardening/softening region. Strength deterioration is incorporated in the stress-strain relationship for each fiber, but cyclic degradation is not modeled in Frame-2d. Geometric nonlinearities (e.g. P$\Delta)$ are accounted for by updating the nodal positions at each time step. Challa and Hall (1994), Hall and Challa (1995), and Hall (1998) validated the special features of Frame-2d by extensive numerical testing and comparison with experimental data. More information about the modeling assumptions for the steel moment-frame models can be found in the work of Buyco (2018). We find the fundamental periods of the 9-, 20-, and 55-story models to be $1.88,3.50$, and $6.12 \mathrm{~s}$, respectively.

It is noted that cyclic degradation can be an important feature to model for collapse simulations (Ibarra et al., 2005), especially for long-duration motions from largemagnitude subduction events (e.g. Kohrangi et al., 2019). None of the motions considered in this article could be described as long-duration motions, and Frame-2d has previously been employed to simulate collapse in response to near-source ground motions (e.g. Hall, 
1998). Nonetheless, it is acknowledged that the cyclic cannot be modeled in Frame-2d, and that this is a limitation.

For each of the three building designs, we develop two models: one with "perfect" (P) moment connections and one with pre-Northridge "brittle" (B) moment connections. The brittle connections model the failures of welded moment connections observed after the 1994 Northridge earthquake. In the models with brittle connections, the short fibers at the end of beam elements that are connected to columns with moment connections represent weld fibers and are assigned a random axial fracture strain according to a user-defined probability distribution. The fracture distributions used in this study are the same as those used by Krishnan and Muto (2012) and similar to those used by Hall (1997), which were calibrated to weld fracture observations in the Northridge earthquake. The results of pushover analysis of all the models considered in this study can be found in the work of Buyco (2018).

For the 9, 20, and 55P models, we perform IDA for each horizontal component of every considered ground motion. We treat the two horizontal components of each record as two individual ground motions and do not consider vertical shaking. For a single model and ground motion, we perform IDA by multiplying the ground motion by a scale factor of 0.1 and performing nonlinear time history analysis in Frame-2d. We repeat this process by incrementing the scale factor by 0.1 for each successive analysis. We continue this process until the scaled ground motion causes collapse of the building model in simulation. In this article, we define collapse in simulation of the steel moment-frame models to be the point at which the building model succumbs to $\mathrm{P}-\Delta$ effects, where the interstory drifts of the model increase without bound, eventually leading to numerical instability. For each individual time history analysis in an IDA, we record the maximum interstory drift ratio (MIDR) for post-processing.

\section{Collapse limit index}

From the results of IDA, we extract for each ground motion, the scale factor at which each of four engineering demand parameters (EDPs) is first elicited in each of the 9, 20, and 55P models. The four EDPs are MIDR $=0.03$, MIDR $=0.06$, MIDR $=0.1$, and collapse in simulation. We choose MIDR $=0.03$, because it is the collapse-prevention limit for many performance-based applications (TBI, 2017). MIDR $=0.06$ is approximately the ultimate limit of modern ductile moment connections (AISC, 2018), at which point failure due to local flange buckling may occur. This is an effect that cannot be captured in Frame-2d. MIDR $=0.1$ corresponds to a severely damaged building and would be considered by some to be the default global collapse limit. Collapse in simulation is equivalent to MIDR $\rightarrow \infty$. All four of the considered EDPs can be interpreted as "collapse limits" depending on the application, and will be referred to as such for the remainder of this article.

For a given collapse limit, ground motion record, and building model, the "collapse limit index" for the record is defined as the scale factor needed to multiply by the record to induce the collapse limit divided by the scale factor needed to multiply by the corresponding tilt-corrected ground motion to induce the collapse limit:

$$
\text { Collapse Limit Index }=\frac{\text { scale factor to induce collapse limit in record }}{\text { scale factor to induce collapse limit in tilt }- \text { corrected record }} \text {. }
$$


For example, for the 20P model and the Chi-Chi TCU084 NS ground motion record, MIDR $=0.06$ is first achieved with a scale factor of 4.6 for the $T_{c}=10 \mathrm{~s}$ filtered record and with a scale factor of 4.3 for the tilt-corrected record. In this case, the collapse limit index is $4.6 / 4.3=1.07$. IDA curves for the $20 \mathrm{P}$ model with the $T_{c}=10$ s filtered and tiltcorrected versions of the Chi-Chi TCU084 NS ground motion record are shown in Figure 6. For a typical IDA curve, the $\mathrm{x}$-axis represents some measure of structural response (e.g. MIDR) and the y-axis represents some measure of the ground motion intensity (e.g. scale factor). Each curve represents a single ground motion and building model. The curve shows how the response of the building model changes as the intensity of the ground motion is increased. Eventually, when the ground motion's scale factor is large enough, the building model will collapse. This is indicated here by MIDR going to infinity. In the IDA curve in Figure 6, one can see visually how the collapse limit indexes are calculated for different collapse definitions (i.e. $\mathrm{MIDR}=0.03, \mathrm{MIDR}=0.06$, and $\mathrm{MIDR}=0.1$ ).

Shown in Figure 7 are histograms of the collapse limit indexes corresponding to collapse in simulation for the 9, 20, and 55P models for records filtered with $T_{c}=10,20$, and $40 \mathrm{~s}$. For comparison, Figure $7 \mathrm{~d}$ shows corresponding collapse limit indexes for the raw records for the ground motions for which raw records are available. If the collapse limit index is 1.00 for a filtered (or raw) record, then the collapse capacity of the structure is the same for the filtered (or raw) record as for the tilt-corrected record.

There are several interesting observations that can be made about Figure 7. First, as would be expected, as $T_{c}$ increases, the collapse limit index for most of the records goes to 1.00. This makes sense because for a filter with larger $T_{c}$, more long-period content remains in the record. It may be surprising, however, that for $T_{c}=10 \mathrm{~s}$, only $41 \%$ of the records have a collapse limit index approximately equal to 1.00 . In particular, there are several records for which the collapse limit index for the 9P model is larger than 1.00 even though $T_{1}$ for the $9 \mathrm{P}$ model is $1.88 \mathrm{~s}$, which would seem to be so much smaller than $T_{c}=10 \mathrm{~s}$ that the application of this filter would not affect the response of the 9P model.

It may also be surprising that for the vast majority of the raw records, the collapse limit index is approximately equal to 1.00 despite the presence of long-period noise in the raw records. In fact, these results imply that one may be better off estimating the collapse capacity of a building model using a raw record than a record filtered with $T_{c}=10$ or $20 \mathrm{~s}$.

To demonstrate how the results vary for different records, the collapse indexes for all records for the 20P model are summarized in Table 3, where collapse is defined to be collapse in simulation. Results are not shown for the $T_{c}=60 \mathrm{~s}$ filter, because they are generally similar to those of the $T_{c}=40 \mathrm{~s}$ filter.

For a more comprehensive summary of the results, statistics of the collapse limit indexes for the 9, 20, and 55P models for all four considered collapse limits are given in Tables 4 and 5. These statistics are meant to summarize corresponding histograms such as those shown in Figure 7. For each collapse limit and building model, the median and 84th percentile collapse limit indexes are reported. For a given collapse limit and building model, the distribution of collapse limit indexes for filtered records tend to be skewed to be greater than 1.00 , so that the median is greater than or equal to 1.00 in all cases. The 16 th percentile is not shown because it is equal or nearly equal to 1.00 in every case.

For comparison, median and 84th percentile collapse limit indexes are reported for the corresponding NGA-West2 records, where available. Note that only 14 of the 52 


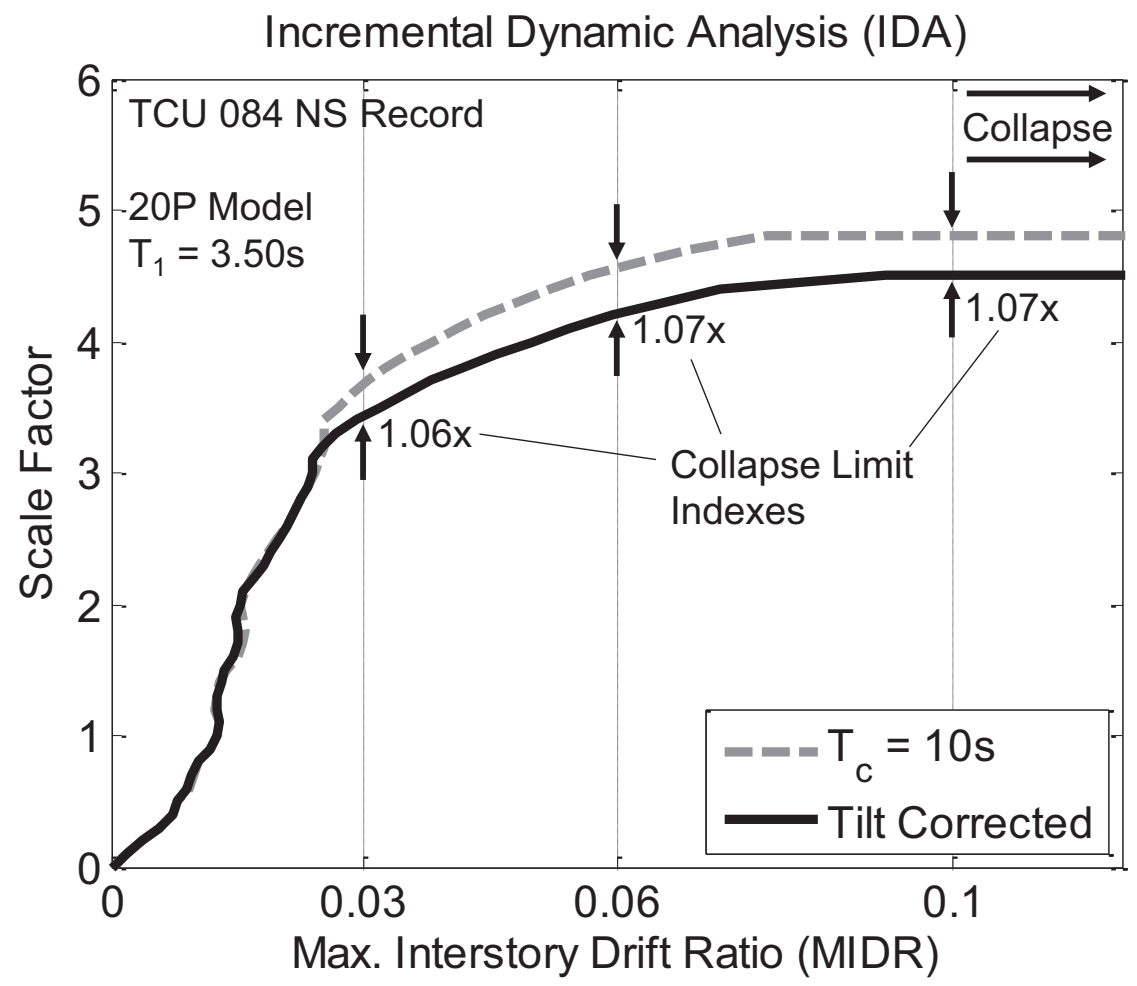

Figure 6. Example of IDA curves and how the collapse limit index is calculated. Here, the 20P model and $T_{c}=10$ s filtered version of the Chi-Chi TCU084 NS ground motion is compared with the tiltcorrected version to calculate the collapse limit index for collapse definitions of MIDR $=0.03$, MIDR $=0.06$, and MIDR $=0.1$. In this case, the scale factor at which MIDR $=0.1$ is reached is when collapse in simulation occurs for both versions of the ground motion. Thus, the collapse limit index is 1.07 both for MIDR $=0.1$ and for collapse in simulation.

considered ground motion record components have corresponding NGA-West2 records. For further comparison, these statistics are also calculated for the corresponding raw records (available for 38 of the 52 components). However, recall that the raw records contain long-period noise which can make ground motion records more destructive. As such, the collapse limit indexes for the raw records tend to be skewed to be less than 1.00. So instead of reporting the 84th percentile (which is equal to 1.00 in almost all cases for the raw records), we report the 16th percentile for the raw records.

The distribution of collapse limit indexes for a given collapse limit and building model are neither normal nor log-normal, but the median and 84th percentile indexes provide insight into the effects of the different filters on structural response. The median measures how a "typical" record is affected by the filters, while the 84th percentile indicates the presence of a few ground motion records that are greatly affected by the filters. Of the filtered records, we see three factors that generally lead to larger median and 84th percentile indexes: more severe collapse limits, taller buildings models, and filters with shorter corner periods. That these three factors lead to larger collapse limit indexes is not surprising. We would expect more severe collapse limits to have higher collapse limit indexes because as buildings experience more damage, their effective period lengthens and they become more 


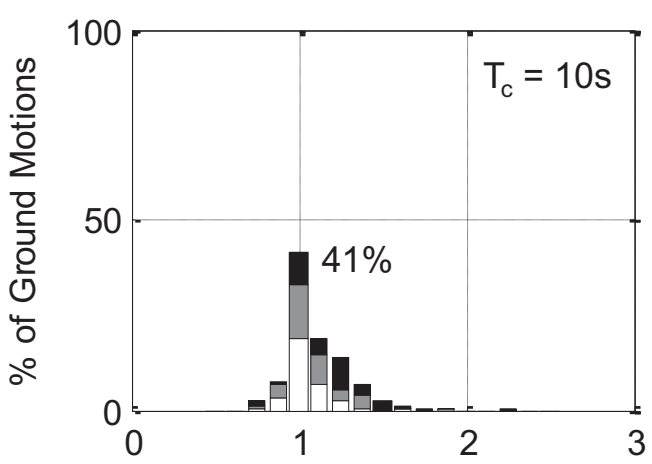

(a)

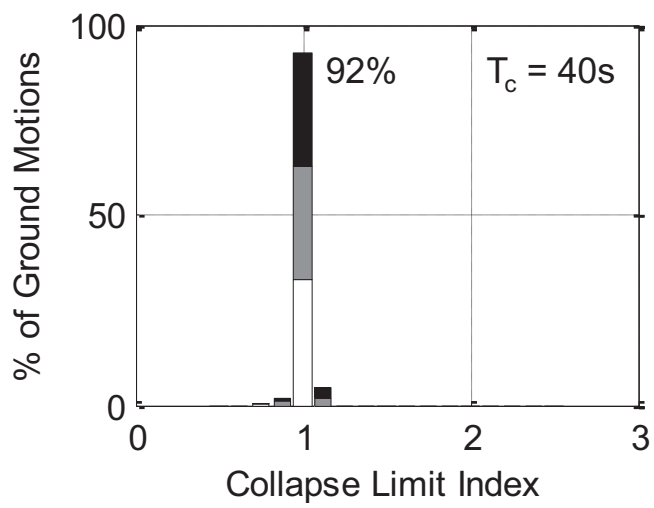

(c)

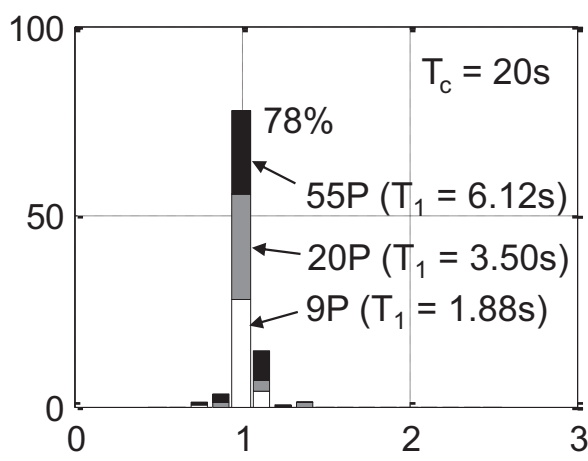

(b)

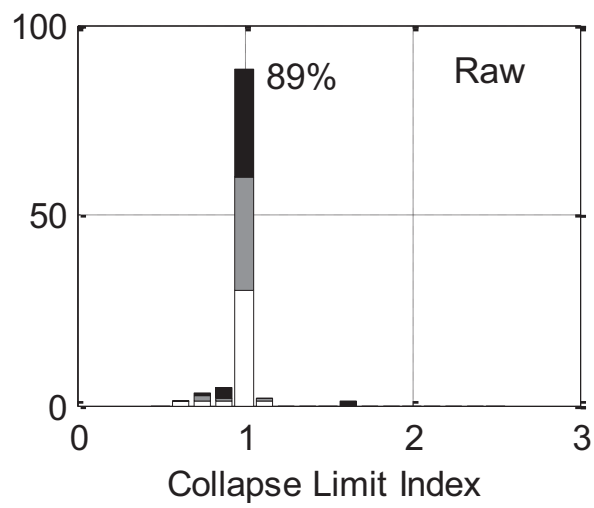

(d)

Figure 7. Histograms of collapse limit indexes for (a) filtered records with $T_{c}=10 \mathrm{~s}$, (b) filtered records with $T_{c}=20 \mathrm{~s}$, (c) filtered records with $T_{c}=40 \mathrm{~s}$, and (d) raw records (where available). The collapse limit is defined here to be collapse in simulation. Each bar in the histograms has a width of I/8 units.

vulnerable to long-period shaking. Similarly, tall building models have longer elastic periods, so we would expect that for a given filter, the effects on a taller building's response would be more significant than that of a shorter building. Finally, filters with shorter corner periods remove more of the original signal than filters with longer corner periods, so it makes sense that they would have more of an effect on structural response.

Except for $T_{c}=10 \mathrm{~s}$, the median collapse limit index is equal to 1.00 in almost all the cases presented in Table 4. This implies that for most ground motions, as long as $T_{c}$ is at least 15-20 s, one can expect that structural response to the processed record will not be dramatically different to that of the tilt-corrected record. However, the 84th percentile collapse limit index is significantly greater than 1.00 in many cases presented in Table 5 for $T_{c}=15$ and $20 \mathrm{~s}$. For example, the results indicate that for about $16 \%$ of the ground motions, the collapse capacity of the $20 \mathrm{P}$ model is at least $8 \%$ larger if the record is processed with $T_{c}=15 \mathrm{~s}$ as opposed to the tilt-corrected record. When combined with the observation that the medians are almost always equal to 1.00 , this means that although the structural responses are not usually affected by these filters in a significant way, there are some cases in which they can have an effect. A few of these cases will be explored in 
Table 3. The collapse limit indexes of the 20P model for all considered ground motion records. For the filtered and NGA-West2 records, the collapse limit index reported here for each record is the maximum of the two components. For the raw records, the collapse limit index reported here for each record is the minimum of the two components. The collapse limit is defined here to be collapse in simulation

\begin{tabular}{|c|c|c|c|c|c|c|c|c|}
\hline Earthquake & Station & $T_{c}=10 \mathrm{~s}$ & $15 \mathrm{~s}$ & $20 \mathrm{~s}$ & $30 \mathrm{~s}$ & $40 \mathrm{~s}$ & NGA-West2 & Raw \\
\hline \multirow{6}{*}{$\begin{array}{l}2016 \\
\text { Kaikōura }\end{array}$} & CULC & 1.21 & 1.07 & 1.07 & 1.06 & 1.06 & - & 1.01 \\
\hline & KEKS & 1.12 & 1.06 & 1.06 & 1.00 & 1.00 & - & 1.00 \\
\hline & KIKS & 1.27 & 1.09 & 1.00 & 1.00 & 1.00 & - & 0.95 \\
\hline & WDFS & 1.09 & 1.00 & 1.00 & 1.07 & 1.00 & - & 1.00 \\
\hline & WIGC & $1.4 \mathrm{I}$ & 1.11 & 1.05 & 1.01 & 1.01 & - & 0.99 \\
\hline & WTMC & 1.06 & 1.04 & 1.04 & 1.02 & 1.02 & - & 1.00 \\
\hline \multirow{9}{*}{$\begin{array}{l}2016 \\
\text { Kumamoto }\end{array}$} & 93048 & 1.00 & 1.00 & 1.00 & 1.00 & 1.00 & - & 0.97 \\
\hline & 93051 & 1.12 & 1.04 & 1.04 & 1.00 & 1.00 & - & 0.94 \\
\hline & KMM00I & 1.02 & 1.00 & 1.00 & 1.00 & 1.00 & - & 1.00 \\
\hline & KMM004 & 1.16 & 1.04 & 1.04 & 1.00 & 1.00 & - & 1.00 \\
\hline & KMM005 & 0.98 & 0.98 & 1.02 & 1.02 & 1.02 & - & 1.00 \\
\hline & KMM007 & 1.43 & 1.33 & 1.35 & 1.07 & 1.04 & - & 1.00 \\
\hline & KMM009 & 1.12 & 1.03 & 1.01 & 1.02 & 1.02 & - & 1.04 \\
\hline & KMMHI6 & 1.38 & 1.09 & 1.03 & 1.03 & 1.00 & - & 0.97 \\
\hline & OІT009 & 1.30 & 1.07 & 1.03 & 1.01 & 1.01 & - & 0.71 \\
\hline \multirow{4}{*}{$\begin{array}{l}2015 \\
\text { Gorkha } \\
2008 \\
\text { Wenchuan }\end{array}$} & KATNP & 1.15 & 1.08 & 1.08 & 1.08 & 1.00 & - & 1.00 \\
\hline & AXT & 1.08 & 1.00 & 0.98 & 0.98 & 1.00 & - & 0.98 \\
\hline & MZQ & 0.96 & 0.96 & 0.96 & 0.96 & 1.00 & - & 0.96 \\
\hline & SFB & 1.05 & 1.05 & 1.05 & 1.02 & 1.02 & - & 0.78 \\
\hline \multirow{2}{*}{\multicolumn{9}{|c|}{$\begin{array}{l}2002 \\
\text { Denali }\end{array}$}} \\
\hline & & & & & & & & \\
\hline \multirow{5}{*}{$\begin{array}{l}1999 \\
\text { Chi-Chi }\end{array}$} & TCU052 & 1.31 & 1.15 & 1.08 & 1.08 & 1.08 & 1.08 & - \\
\hline & TCU065 & 1.19 & 1.06 & 1.05 & 1.00 & 1.00 & 1.05 & _- \\
\hline & TCU067 & 1.15 & 1.05 & 1.02 & 1.02 & 1.00 & 1.00 & - \\
\hline & TCU068 & 1.88 & 1.25 & 1.13 & 1.13 & 1.13 & 1.13 & - \\
\hline & TCU084 & 1.07 & 1.05 & 1.05 & 1.05 & 1.05 & 1.10 & - \\
\hline $\begin{array}{l}1992 \\
\text { Landers }\end{array}$ & LUC & 1.42 & 1.63 & 1.42 & 1.05 & 1.00 & 1.37 & - \\
\hline
\end{tabular}

more detail later in this article. It appears that if $T_{c}=30$ or $40 \mathrm{~s}$, the structural responses are mostly unaffected, even judging from the 84th percentiles.

The structural responses from the raw records are very similar to those of the tiltcorrected records. In every case, the median collapse limit index is 1.00 for the raw records. Qualitatively, the reported 16th percentile indexes are similarly far from 1.00 as the 84th percentile indexes for records filtered with $T_{c}=20$ or $30 \mathrm{~s}$. This leads to the interesting conclusion that, at least for the considered ground motion records, applying a high-pass filter with $T_{c}<20 \mathrm{~s}$ to remove long-period noise can remove so much of the actual longperiod content in the record that the structural response from the raw record is closer to the response from the tilt-corrected record than to the response from the filtered record.

The statistics from the NGA-West 2 ground motions show some surprising behavior. Although, like the filtered ground motions, the median collapse limit index equals 1.00 in 
Table 4. The median collapse limit indexes for the (a) 9P, (b) 20P, and (c) 55P models calculated based on results from all considered ground motion records

\begin{tabular}{|c|c|c|c|c|c|c|c|}
\hline \multirow[t]{2}{*}{ Collapse limit } & \multicolumn{7}{|c|}{ Median collapse limit index } \\
\hline & $T_{c}=10 \mathrm{~s}$ & $15 \mathrm{~s}$ & $20 \mathrm{~s}$ & $30 \mathrm{~s}$ & $40 \mathrm{~s}$ & NGA-West2 & Raw \\
\hline \multicolumn{8}{|l|}{ (a) 9P } \\
\hline MIDR $=0.03$ & 1.00 & 1.00 & 1.00 & 1.00 & 1.00 & 1.00 & 1.00 \\
\hline MIDR $=0.06$ & I.0I & 1.00 & 1.00 & 1.00 & 1.00 & 1.00 & 1.00 \\
\hline MIDR = 0.1 & 1.03 & 1.00 & 1.00 & 1.00 & 1.00 & 1.00 & 1.00 \\
\hline Collapse in sim. & 1.02 & 1.00 & 1.00 & 1.00 & 1.00 & 1.00 & 1.00 \\
\hline \multicolumn{8}{|l|}{ (b) $20 \mathrm{P}$} \\
\hline MIDR $=0.03$ & 1.03 & 1.00 & 1.00 & 1.00 & 1.00 & 1.00 & 1.00 \\
\hline MIDR $=0.06$ & 1.06 & 1.00 & 1.00 & 1.00 & 1.00 & 1.00 & 1.00 \\
\hline MIDR = 0.1 & 1.05 & 1.00 & 1.00 & 1.00 & 1.00 & 1.00 & 1.00 \\
\hline Collapse in sim. & 1.06 & 1.00 & 1.00 & 1.00 & 1.00 & 1.02 & 1.00 \\
\hline \multicolumn{8}{|l|}{ (c) $55 \mathrm{P}$} \\
\hline MIDR $=0.03$ & 1.00 & 1.00 & 1.00 & 1.00 & 1.00 & 1.00 & $\mathrm{I} .00$ \\
\hline MIDR $=0.06$ & I.II & 1.01 & 1.00 & 1.00 & 1.00 & 1.00 & 1.00 \\
\hline MIDR = 0.1 & 1.15 & 1.03 & 1.00 & 1.00 & 1.00 & 1.00 & 1.00 \\
\hline Collapse in sim. & 1.20 & 1.03 & 1.02 & 1.00 & 1.00 & 1.00 & 1.00 \\
\hline
\end{tabular}

MIDR: maximum interstory drift ratio.

Table 5. The 84th percentile collapse limit indexes for the (a) 9P, (b) 20P, and (c) 55P models calculated based on results from all considered ground motion records. The 16 th percentile is reported for the raw records because the 84 th percentile is equal to 1.00 in all cases

\begin{tabular}{|c|c|c|c|c|c|c|c|}
\hline \multirow[t]{2}{*}{ Collapse limit } & \multicolumn{6}{|c|}{ 84th percentile collapse limit index } & \multirow{2}{*}{$\begin{array}{l}\text { 16th } \\
\text { Raw }\end{array}$} \\
\hline & $T_{c}=10 \mathrm{~s}$ & $15 \mathrm{~s}$ & $20 \mathrm{~s}$ & $30 \mathrm{~s}$ & $40 \mathrm{~s}$ & NGA-West2 & \\
\hline \multicolumn{8}{|l|}{ (a) $9 P$} \\
\hline MIDR $=0.03$ & 1.08 & 1.03 & 1.00 & 1.00 & 1.00 & 1.00 & 1.00 \\
\hline MIDR $=0.06$ & 1.08 & 1.04 & 1.02 & 1.00 & 1.00 & 1.00 & 0.99 \\
\hline MIDR = 0.1 & 1.12 & 1.06 & 1.04 & 1.02 & 1.02 & 1.03 & 0.97 \\
\hline $\begin{array}{l}\text { Collapse in sim. } \\
\text { (b) } 20 \mathrm{P}\end{array}$ & 1.14 & 1.07 & 1.06 & 1.03 & 1.02 & 1.05 & 0.98 \\
\hline MIDR $=0.03$ & 1.15 & 1.07 & 1.04 & 1.00 & 1.00 & 1.03 & 0.99 \\
\hline MIDR $=0.06$ & 1.17 & 1.09 & 1.05 & 1.03 & 1.01 & 1.07 & 0.95 \\
\hline MIDR = 0.1 & 1.21 & 1.09 & 1.05 & 1.02 & 1.01 & I.II & 0.96 \\
\hline $\begin{array}{l}\text { Collapse in sim. } \\
\text { (c) } 55 \mathrm{P}\end{array}$ & 1.28 & 1.08 & 1.05 & 1.03 & 1.02 & 1.12 & 0.96 \\
\hline MIDR $=0.03$ & 1.18 & 1.06 & 1.02 & 1.02 & 1.00 & I.II & 0.96 \\
\hline MIDR $=0.06$ & 1.27 & 1.08 & 1.05 & 1.02 & 1.01 & 1.09 & 0.96 \\
\hline MIDR = 0.1 & $\mathrm{I} .34$ & 1.13 & 1.07 & 1.03 & 1.03 & 1.08 & 0.96 \\
\hline Collapse in sim. & $\mathrm{I} .44$ & 1.17 & 1.09 & 1.07 & 1.03 & 1.12 & 0.98 \\
\hline
\end{tabular}

MIDR: maximum interstory drift ratio.

most cases for the NGA-West2 records, the 84th percentile can be up to 1.10 , or larger. These results are somewhat skewed by the fact that there are only 14 NGA-West 2 records considered here, so the 84th percentile is controlled by only a few records, and may not be stable - that is, the 84th percentile values may change if a more comprehensive set of ground motions were analyzed. To investigate this further, we briefly analyze the Landers 
LUC FN record, for which the collapse limit index for the NGA-West2 record is 1.37 for the 20P model experiencing collapse in simulation, which is particularly surprising because the NGA-West 2 flatfile indicates that the record is not high-pass filtered.

20P model and the Landers LUC FN record. Figure 8 compares the NGA-West2 and tiltcorrected Landers LUC FN records. The only difference we would expect between these two records is a static offset in the displacement time series corresponding to a sixth-order polynomial fit that is removed as part of the NGA-West 2 processing procedure. Figure $8 \mathrm{a}$ compares the displacement time series of the NGA-West2 and tilt-corrected Landers LUC FN records. These time series are also shown in Figure 5d, and here, we also explicitly plot the difference between the two records, which is essentially equivalent to a sixth-order polynomial fit to the tilt-corrected record. Figure $8 \mathrm{~b}$ compares the $5 \%$-damped acceleration response spectra of the two records and indicates $T_{1}$ for the $20 \mathrm{P}$ model, which is $3.50 \mathrm{~s}$. Despite the obvious differences in the displacement time series, the two records have almost identical response spectra, though it should be noted that the spectral acceleration at $T=3.50 \mathrm{~s}$ for the NGA-West 2 record is slightly larger (by $5.5 \%$ ) than that for the tilt-corrected record.

Figure $8 \mathrm{c}$ compares IDA curves of the NGA-West2 and tilt-corrected Landers LUC FN records. Despite the fact that the response spectra are nearly identical, the collapse capacities (i.e. the scale factor at which collapse first occurs) for the two records are notably different (by 37\%). The responses are nearly identical for drifts up to about MIDR $=0.06$, it is only when the structure begins to experience highly nonlinear response (i.e. MIDR > 0.06) that the results from the two records diverge. Note that collapse limit indexes corresponding to other definitions of collapse (i.e. MIDR $=0.03,0.06$, and 0.1 ) could easily be extracted from these IDA curves.

Figure $8 \mathrm{~d}$ plots the 4 th-story drift over time of the $20 \mathrm{P}$ model in response to $1.9 \mathrm{x}$ the tilt-corrected record (which induces collapse), 2.6x the NGA-West2 record (which induces collapse), and 1.9x the NGA-West2 record (which does not induce collapse). The 4th story is chosen because this the story in which the maximum drift occurs in response to the $1.9 \mathrm{x}$ NGA-West 2 record. It is evident that as the ground motions begin their pulses at about $t=10 \mathrm{~s}$, the 4th-story drift becomes large in the opposite direction. After about $t=10 \mathrm{~s}$, the structure swings dramatically in the direction of the pulse and eventually the building collapses in this direction in response to $1.9 \mathrm{x}$ the tilt-corrected record and to $2.6 \mathrm{x}$ the NGA-West2 record, but not 1.9x the NGA-West2 record.

To further investigate the behavior of the 20P model in these records, Figure 9 plots the story drift ratios up the height of the building in response to $1.9 \mathrm{x}$ the tilt-corrected record, $1.9 \mathrm{x}$ the NGA-West2 record, and $2.6 \mathrm{x}$ the NGA-West2 record at $t=10.45 \mathrm{~s}$ and $\mathrm{t}=13.35 \mathrm{~s}$. These two values of $t$ during the record are chosen because the MIDR of the $20 \mathrm{P}$ model in response to $1.9 \mathrm{x}$ the NGA-West 2 record in the negative direction occurs at $t=10.45 \mathrm{~s}$ and in the positive direction occurs at $13.35 \mathrm{~s}$. In all three motions, large drifts are concentrated near the base of the building. For 1.9x the NGA-West2 record, drifts at $t=10.45 \mathrm{~s}$ are slightly more intense in the negative direction than those for $1.9 \mathrm{x}$ the tiltcorrected record. At $t=13.35 \mathrm{~s}$, at which time the building has swung in the positive direction, the reverse is observed - for 1.9x the tilt-corrected record, drifts are more intense in the positive direction (and eventually induce collapse) than those for 1.9x the NGAWest 2 record. It appears that, because $1.9 \mathrm{x}$ the NGA-West 2 record initially swings the building in the negative direction further than $1.9 \mathrm{x}$ the tilt-corrected record, $1.9 \mathrm{x}$ the 


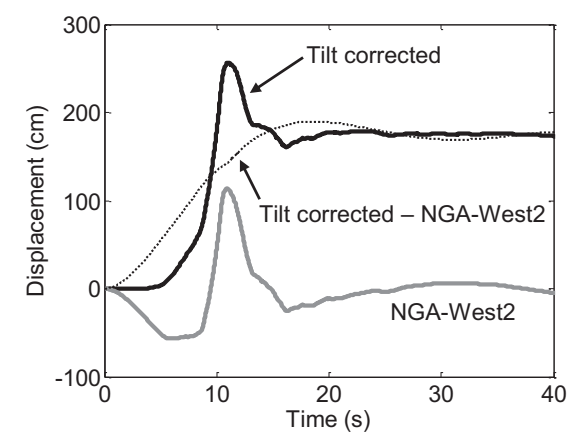

(a)

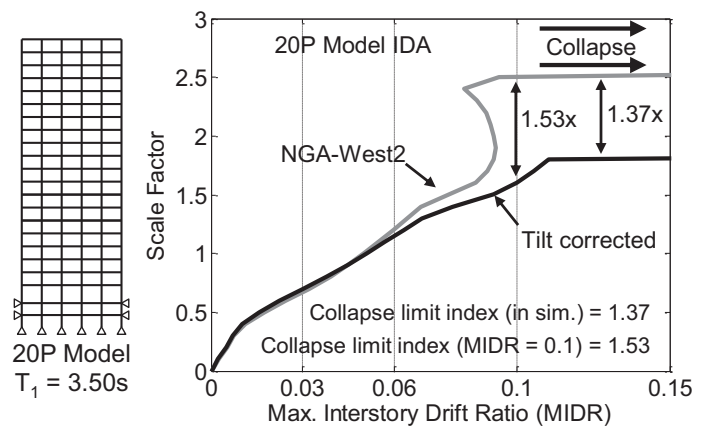

(c)

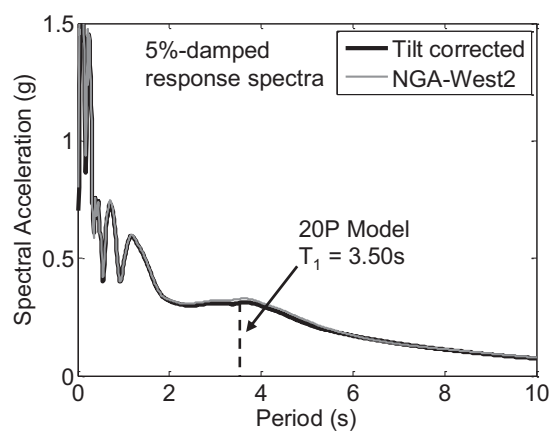

(b)

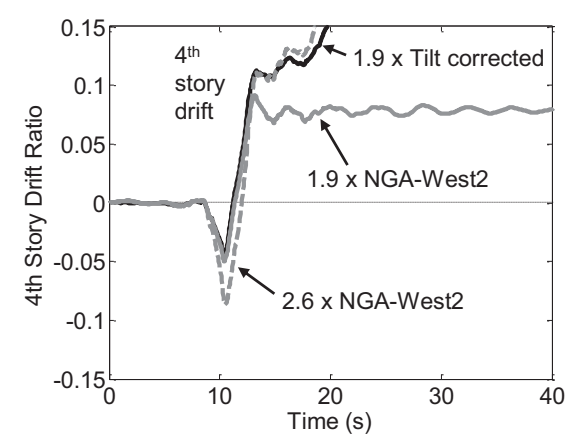

(d)

Figure 8. (a) Displacement time series of the Landers LUC FN tilt-corrected and NGA-West2 records. The difference between the two records is also shown. (b) Response spectra of the Landers LUC FN tilt-corrected and NGA-West2 records. (c) IDA curves when the Landers LUC FN tilt-corrected and NGA-West2 records are input into the 20P model, for which $T_{1}=3.50 \mathrm{~s}$. The collapse limit is defined here to be collapse in simulation. (d) 4th-story drift ratio time histories of the 20P model in response to scaled versions of the Landers LUC FN tilt-corrected and NGA-West2 records. The 4th story is shown because this the story in which the maximum drift occurs in response to 1.9x the NGA-West2 record.

NGA-West 2 record results in lesser drifts in the positive direction when the building swings back.

For scale factors between $1.9 \mathrm{x}$ and $2.6 \mathrm{x}$ for the NGA-West2 record, collapse is not induced in the 20P model because the initial drifts in the negative direction that occur around $t=10 \mathrm{~s}$ causes enough yielding that the building swings even less in the direction of the pulse (i.e. in the positive direction) and thus has even smaller MIDR as the scale factor increases. The results of this can be seen in the negative slope of Figure $8 \mathrm{c}$ for the NGA-West 2 record for scale factors between $1.9 \mathrm{x}$ and 2.6x. This is known as "severe hardening" and is discussed later in this article.

Interestingly, the collapse limit index for the $T_{c}=40 \mathrm{~s}$ filtered version of the Landers LUC FN record is exactly equal to 1.00 for the $20 \mathrm{P}$ model. Recall that for the filtered ground motions, we apply filters directly to the tilt-corrected ground motions. Thus, in the case of the Landers LUC FN record and the 20P model, removing a sixth-order polynomial fit to the tilt-corrected record has more of an effect on structural response than applying a high-pass filter with $T_{c}=40 \mathrm{~s}$. 


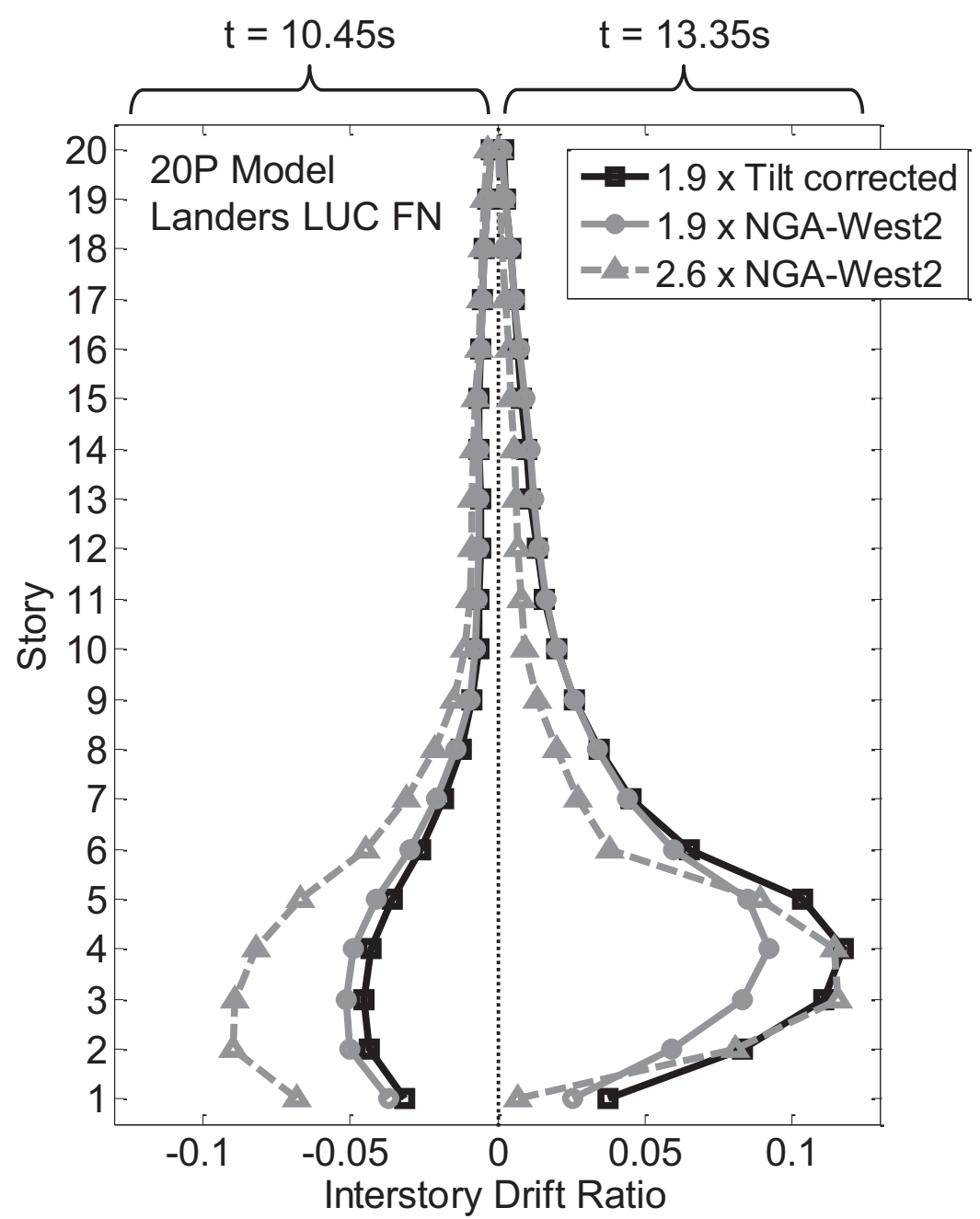

Figure 9. Interstory drift ratios of the 20P model in response to scaled versions of the Landers LUC FN tilt-corrected and NGA-West2 records at $t=10.45 \mathrm{~s}$ and $t=13.35 \mathrm{~s}$. These two values of $t$ during the record are chosen because the maximum drift ratio of the 20P model in response to $1.9 x$ the NGAWest2 record in the negative direction occurs at $t=10.45 \mathrm{~s}$ and in the positive direction occurs at $13.35 \mathrm{~s}$.

\section{Results from strongest ground motion records}

To show the aforementioned effects of high-pass filters for individual ground motions and building models, we consider the ground motion record component from each earthquake that has the largest PGV: Kaikoura KEKS EW, Kumamoto 93048 EW, Gorkha KATNP EW, Wenchuan MZQ EW, Denali PS10 FN, Chi-Chi TCU 068 NS, Denali PS10 FN, and Landers LUC FN. We refer to these as the "strongest" ground motion records. The effects of the filters on PGV for these seven records were shown previously in Table 5. In addition to the results presented in the previous section for the $\mathrm{P}$ models, we perform IDA with these seven ground motions on the three B models $(9 \mathrm{~B}, 20 \mathrm{~B}$, and $55 \mathrm{~B})$ with the tilt- 
Table 6. The collapse limit indexes of all considered building models for the strongest ground motion records for which a corresponding raw records are available. The collapse limit is defined here to be collapse in simulation

\begin{tabular}{lllllll}
\hline Record & \multicolumn{7}{l}{ Collapse limit indexes for raw records } \\
\cline { 2 - 7 } & $9 \mathrm{P}$ & 20P & $55 \mathrm{P}$ & $9 \mathrm{~B}$ & $20 \mathrm{~B}$ & 55B \\
\hline Kaikōura KEKS EW & 1.00 & 1.00 & 1.00 & 1.00 & 1.00 & 0.94 \\
Kumamoto 93048 EW & 1.00 & 1.00 & 1.00 & 1.00 & 1.00 & 1.00 \\
Gorkha KATNP EW & 1.00 & 1.00 & 1.00 & 0.93 & 1.00 & 1.04 \\
Wenchuan MZQ EW & 1.00 & 0.96 & 0.93 & 1.00 & 1.00 & 0.97 \\
\hline
\end{tabular}

corrected and filtered versions of these records. Where available, we also perform IDA with the raw and NGA-West2 versions of these records.

To summarize the results, we calculate the collapse limit index for collapse in simulation for every available version of every ground motion. The results for the filtered records are shown in Figure 10 and the results for the raw and NGA-West 2 records are shown in Tables 6 and 7, respectively.

Figure 10 shows that the collapse limit index is usually close to 1.00 , but in some cases, particularly for $T_{c}=10$ or $15 \mathrm{~s}$, the collapse limit index can be significantly greater than 1.00. This is not surprising, as the same conclusions were drawn from Tables 4 and 5. Tables 6 and 7 also show the same trends as Tables 4 and 5 with regards to raw and NGAWest 2 records. That is, the collapse limit index is always close to 1.00 for the raw records, while it can vary greatly for the NGA-West 2 records. For these seven strong ground motions, the 55B model appears to be the most susceptible to the effects of filtering input ground motions. We hypothesize that this is because the 55B model has widest variety of different possible collapse mechanisms.

To take a closer look at how the collapse limit index varies by ground motion and building model, IDA curves for $T_{c}=10,20$, and $40 \mathrm{~s}$, and tilt-corrected versions of the Kaikoura KEKS EW, Chi-Chi TCU068 NS, and Landers LUC FN records are shown in Figures 11 to 13 for all six building models. The results from the Kaikōura KEKS EW record are typical of most records - the application of the high-pass filters do not have a large impact on structural response. However, in some cases these filters can have a dramatic impact, and the IDA curves from the Chi-Chi TCU068 NS and Landers LUC FN records are shown for this reason.

As evidenced in Figures 12 and 13, the high-pass filters can sometimes have a dramatic effect on the collapse capacity of the building models. The 55B model's collapse capacity for both the Chi-Chi TCU068 NS and Landers LUC FN ground motions increases by more than $300 \%$ when a $T_{c}=10 \mathrm{~s}$ high-pass filter is applied, due to a phenomenon known as "severe hardening" (Vamvatsikos and Cornell, 2002) which is indicated by a negative slope in the IDA curve. Severe hardening occurs for the $55 \mathrm{~B}$ model for both ground motions for the $T_{c}=10 \mathrm{~s}$ filtered versions, but not in the tilt-corrected versions, because its collapse mechanism is different for the $T_{c}=10 \mathrm{~s}$ filtered ground motion. For example, for the Landers LUC FN record, the tilt-corrected version first induces collapse in the 55B model with a scale factor of 1.2 and large drifts are concentrated in stories 2545. The $T_{c}=10 \mathrm{~s}$ filtered version of the same record first induces collapse in the same model with a scale factor of 4.5 and large drifts are concentrated in stories 1-10. For 
Table 7. The collapse limit indexes of all considered building models for the strongest ground motion records for which corresponding NGA-West2 records are available. The collapse limit is defined here to be collapse in simulation

\begin{tabular}{lllllll}
\hline Record & \multicolumn{7}{l}{ Collapse limit indexes for NGA-West2 records } \\
\cline { 2 - 7 } & $9 \mathrm{P}$ & 20P & $55 \mathrm{P}$ & $9 \mathrm{~B}$ & $20 \mathrm{~B}$ & $55 \mathrm{~B}$ \\
\hline Denali PSI0 FP & 0.90 & 1.00 & 1.02 & 0.82 & 1.06 & 1.76 \\
Chi-Chi TCU068 NS & 1.00 & 1.13 & 1.11 & 1.00 & 1.00 & 1.20 \\
Landers LUC FN & 0.96 & 1.37 & 1.09 & 1.00 & 1.00 & 1.08 \\
\hline
\end{tabular}

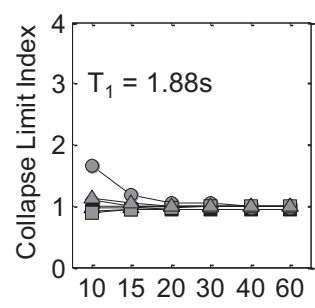

(a)

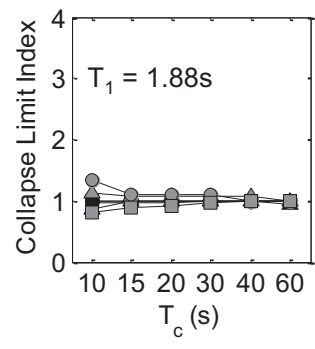

(d)

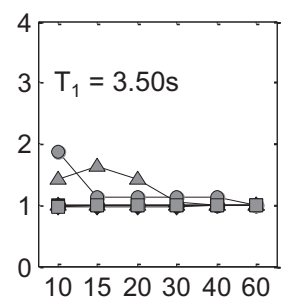

(b)

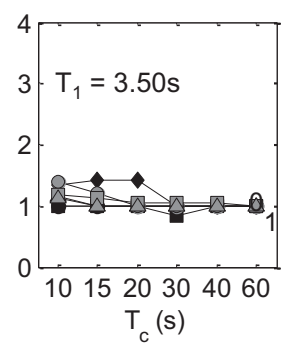

(e)
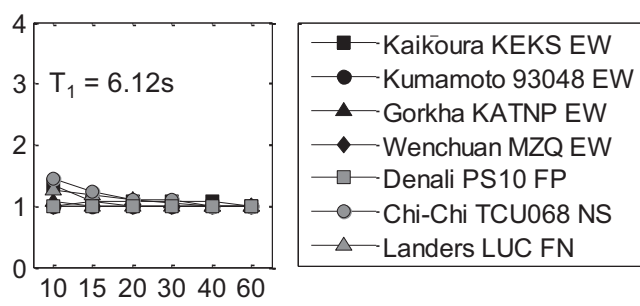

(c)

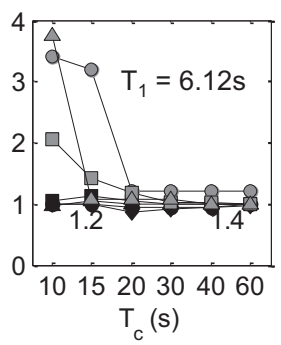

(f)

Figure 10. The collapse limit indexes of all considered building models for the filtered versions of the strongest ground motion records with different $T_{c}$. The collapse limit is defined here to be collapse in simulation. (a) $9 \mathrm{P}, T_{1}=1.88 \mathrm{~s}$; (b) $20 \mathrm{P}, T_{1}=3.50 \mathrm{~s}$; (c) $55 \mathrm{P}, T_{1}=6.12 \mathrm{~s}$ (d) $9 \mathrm{~B}, T_{1}=1.88 \mathrm{~s}$; (e) $20 \mathrm{~B}$, $T_{1}=3.50 \mathrm{~s} ;$ (f) $55 \mathrm{~B}, T_{1}=6.12 \mathrm{~s}$.

reference, when the $T_{c}=10 \mathrm{~s}$ filtered version scaled is by $1.2 \mathrm{x}$, large drifts are concentrated in stories $30-45$ in the $55 \mathrm{~B}$ model, but the drifts are not quite large enough to induce collapse. As the scale factor is increased, the concentration of large drifts shifts to stories 1-10 and much larger scale factor is needed to induce collapse.

In addition to the 55B model, we also see this phenomenon to a lesser extent in the IDA curve of the 20P model for the Landers LUC FN record, which has been discussed previously in this article. These large collapse limit indexes due to changes in collapse mechanisms for increasing scale factors are "unlucky" in a sense and cannot always be known a priori, but it appears to be more likely to occur in taller buildings, for which there are more potential collapse mechanisms.

Another surprising observation is that the collapse capacities of the 9P and 9B models $\left(T_{1}=1.88 \mathrm{~s}\right)$ to the Chi-Chi TCU068 NS record increase significantly (by more than $50 \%$ 


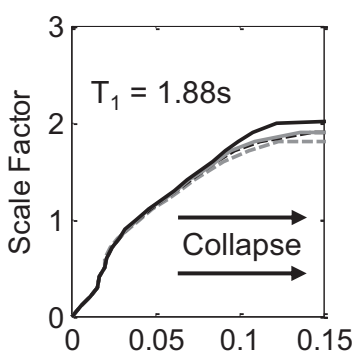

(a)

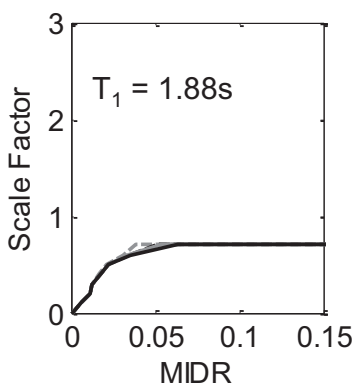

(d)

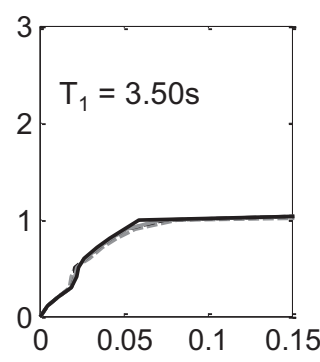

(b)

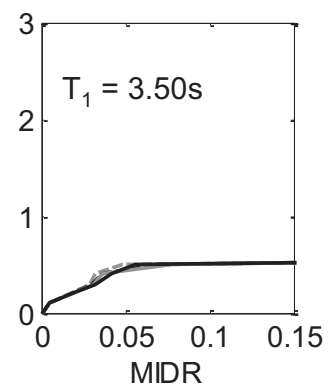

(e)
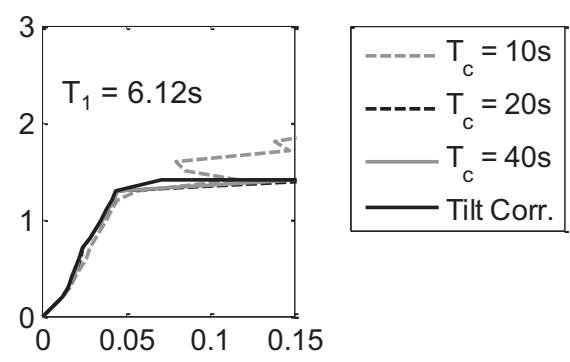

(c)

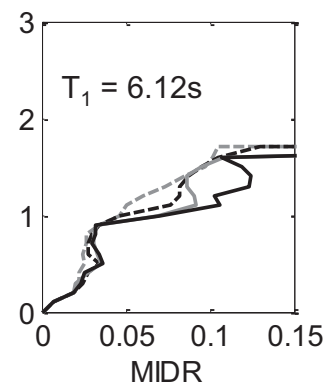

(f)

Figure II. IDA curves of all considered building models for the tilt-corrected Kaikōura KEKS EW ground motion record and its filtered versions with $T_{c}=10,20$, and $40 \mathrm{~s}$. (a) $9 \mathrm{P}, T_{1}=1.88 \mathrm{~s}$; (b) 20P, $T_{1}=3.50 \mathrm{~s}$; (c) $55 \mathrm{P}, T_{1}=6.12 \mathrm{~s}$; (d) $9 \mathrm{~B}, T_{1}=1.88 \mathrm{~s}$; (e) $20 \mathrm{~B}, T_{1}=3.50 \mathrm{~s}$; (f) $55 \mathrm{~B}, T_{1}=6.12 \mathrm{~s}$.

for the 9P model) after application of the filter with $T_{c}=10 \mathrm{~s}$ to the tilt-corrected ground motion ( Figure 12a and d). This is surprising because $T_{c}$ is more than $5 \times$ greater than $T_{1}$ in this case and one may have assumed that removing long-period content at periods so much larger than $T_{1}$ would not affect building response.

This observation occurs because the Chi-Chi TCU068 NS record contains significant long-period content not seen in any other record. This can be seen in Figure 14, which shows the 5\%-damped response spectra for the $T_{c}=10,20,40 \mathrm{~s}$, and tilt-corrected versions of the Kaikoura KEKS EW, Chi-Chi TCU068 NS, and Landers LUC FN records. Figure $14 \mathrm{~d}$ to $\mathrm{f}$ plots the surface area ("SA") ratio for each record, where:

$$
\text { SA Ratio }=\frac{5 \%-\text { damped response spectrum of record }}{5 \%-\text { damped response spectrum of tilt }- \text { corrected record }} \text {. }
$$

The response spectra and SA ratio plots corresponding to the Kaikoura KEKS EW (Figure 14a and d) and Landers LUC FN (Figure 14c and f) records are typical of most of the considered ground motions. The response spectra of the $T_{c}=10 \mathrm{~s}$ versions of these records only deviate from the tilt-corrected versions for $T>6 \mathrm{~s}$, with the deviation gradually increasing until about $T=10 \mathrm{~s}$. For these records, the SA ratio drops below 0.9 only for $T>6 \mathrm{~s}$.

In comparison, the SA ratio of the $T_{c}=10 \mathrm{~s}$ version of the Chi-Chi TCU068 NS record is less than 0.9 over a lower range of periods - from about $T=3.5$ to $5 \mathrm{~s}$. The literal interpretation is that, for SDOFs with $T$ ranging from 3.5 to $5 \mathrm{~s}$, a significant portion 


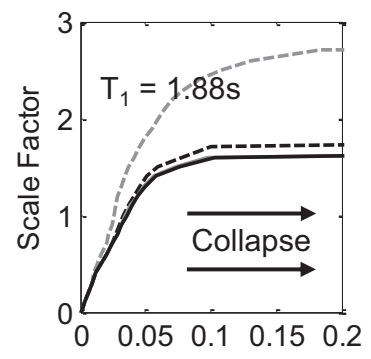

(a)

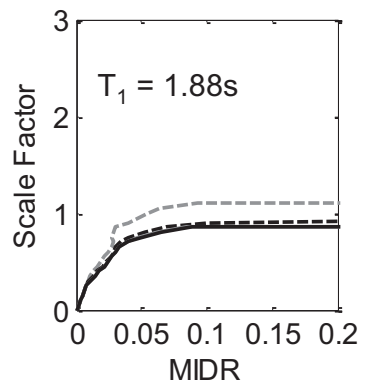

(d)

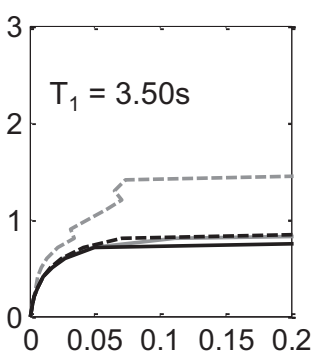

(b)

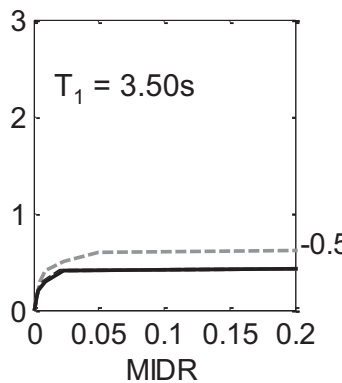

(e)

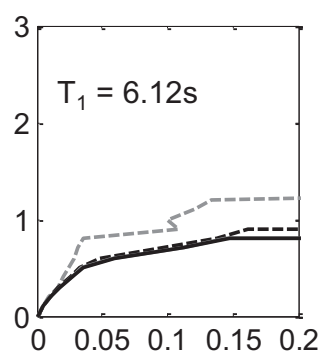

(c)

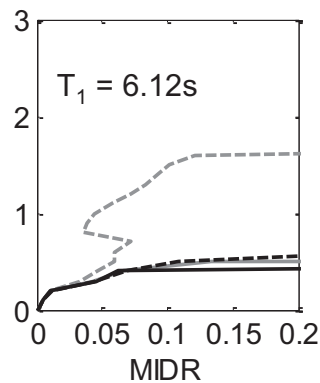

(f)

Figure 12. IDA curves of all considered building models for the tilt-corrected Chi-Chi TCU068 NS ground motion record and its filtered versions with $T_{c}=10,20$, and $40 \mathrm{~s}$. (a) $9 \mathrm{P}, T_{1}=1.88 \mathrm{~s}$; (b) 20P, $T_{1}=3.50 \mathrm{~s}$; (c) $55 \mathrm{P}, T_{1}=6.12 \mathrm{~s}$; (d) $9 \mathrm{~B}, T_{1}=1.88 \mathrm{~s}$; (e) $20 \mathrm{~B}, T_{1}=3.50 \mathrm{~s}$; (f) $55 \mathrm{~B}, T_{1}=6.12 \mathrm{~s}$.

of the response to the tilt-corrected Chi-Chi TCU068 NS record is driven by long-period content that is removed with the application of a high-pass filter with $T_{c}=10 \mathrm{~s}$. It is not surprising, then, that the collapse capacities of all the considered models, even that of the 9P model with $T_{1}=1.88 \mathrm{~s}$, are different for the $T_{c}=10 \mathrm{~s}$ and tilt-corrected versions of the Chi-Chi TCU068 NS record (see Figure 12). In fact, one could have predicted the effects on the 9P model before performing IDA by simply analyzing the SA ratio plots. Recall that ASCE 7-16 requires ground motions selected for nonlinear time history analysis to match the target spectrum at periods up to $2 T_{1}$ (ASCE, 2016). For the 9P model, $2 T_{1}=3.76 \mathrm{~s}$, so upon analysis of the SA ratio plots for the Chi-Chi TCU068 NS record, one could have observed that the response spectra of the $T_{c}=10 \mathrm{~s}$ and tilt-corrected versions of the Chi-Chi TCU068 NS record are significantly different (by 22\%) at $2 T_{1}$ and predicted that the collapse capacities for the 9P model would be different for the two records. Crucially, these results demonstrate that applying a high-pass filter with corner period $T_{c}$ does not imply that the response spectrum is unaffected for periods even much less than $T_{c}$.

Despite the observation that one could have predicted that the collapse capacities of the considered models would be different for the $T=10 \mathrm{~s}$ and tilt-corrected versions of the Chi-Chi TCU068 NS record, the same is not true for the $T_{c}=20 \mathrm{~s}$ and tilt-corrected versions of the Landers LUC FN record. Figure 13b shows that the collapse capacity of the $20 \mathrm{P}$ model is significantly higher (collapse limit index $=1.42$ ) for the $T_{c}=20 \mathrm{~s}$ version than for the tilt-corrected version, where collapse is defined as collapse in simulation. It is evident that this could not have been predicted by simply analyzing the SA ratio plots. As seen in Figure 14f, the SA ratio for the $T_{c}=20 \mathrm{~s}$ version of the Landers LUC FN record 


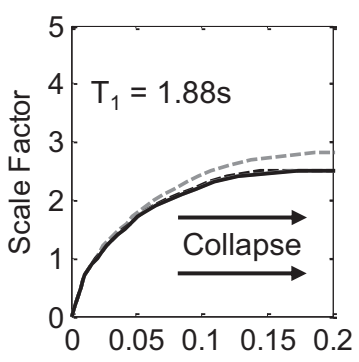

(a)

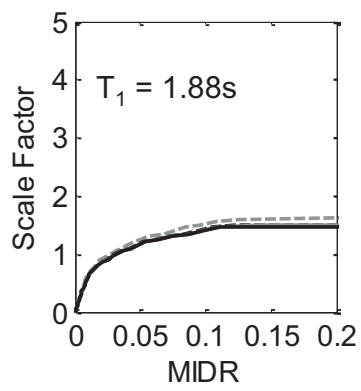

(d)

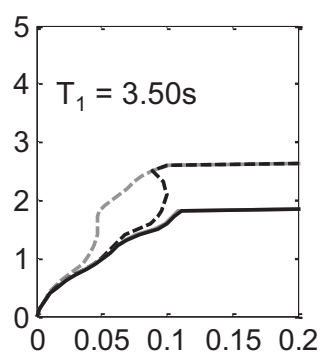

(b)

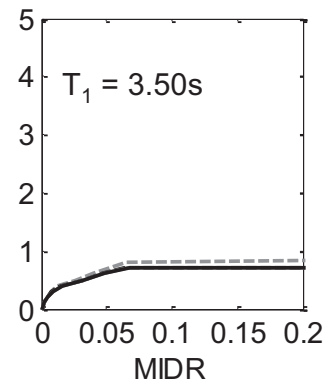

(e)
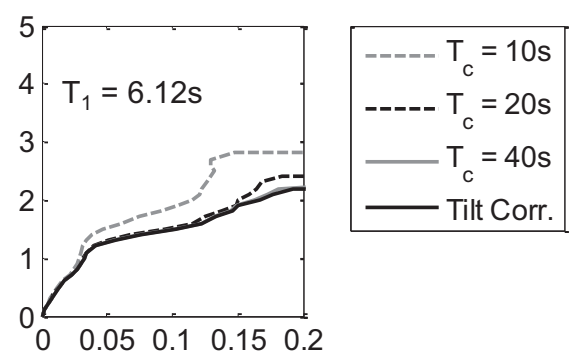

(c)

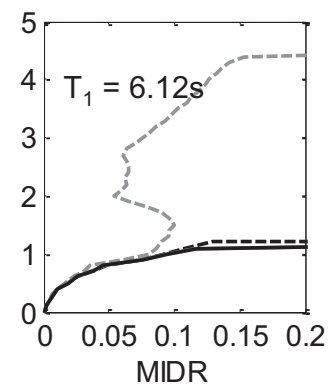

(f)

Figure 13. IDA curves of all considered building models for the tilt-corrected Landers LUC FN ground motion record and its filtered versions with $T_{c}=10,20$, and $40 \mathrm{~s}$. (a) $9 \mathrm{P}, T_{1}=1.88 \mathrm{~s}$; (b) 20P, $T_{1}=3.50 \mathrm{~s}$; (c) $55 \mathrm{P}, T_{1}=6.12 \mathrm{~s}$; (d) $9 \mathrm{~B}, T_{1}=1.88 \mathrm{~s}$; (e) $20 \mathrm{~B}, T_{1}=3.50 \mathrm{~s}$; (f) $55 \mathrm{~B}, T_{1}=6.12 \mathrm{~s}$.

does not drop below 0.96 for any period less than $10 \mathrm{~s}$, which is about three times larger than $T_{1}=3.50 \mathrm{~s}$ for the $20 \mathrm{P}$ model. Instead, as discussed previously, "severe hardening" plays a role in causing unpredictable changes in the collapse capacity. Therefore, one cannot conclude that a high-pass filter will have no effect on the collapse capacity for a record and building model simply by analyzing the response spectra of the filtered and unfiltered records.

\section{Conclusion}

We find that there are a number of cases in which applying high-pass filters to ground motion records can affect the structural response to these records. Not surprisingly, these effects are most notable for more severe collapse limits, taller buildings (i.e. models with longer $T_{1}$ ), and high-pass filters with shorter $T_{c}$. These effects are not usually significant, but we find that in some cases, the collapse capacity of a structure can change by over $50 \%$ if a high-pass filter is applied to a tilt-corrected record. In cases where these effects are present, the collapse capacities of building models to filtered ground motions tend to be higher than to corresponding tilt-corrected ground motions.

In practice, it is assumed that records selected from the NGA-West2 database are suitable for nonlinear time history analysis if the maximum usable period $\left(80 \%\right.$ of $\left.T_{c}\right)$ is greater than $1.5 T_{1}$ or $2 T_{1}$. We find in some cases that this limit is not sufficient. For the Chi-Chi TCU068 NS record, applying a high-pass filter with $T_{c}=10 \mathrm{~s}$ increased the collapse capacity of the $9 \mathrm{P}$ model $\left(T_{1}=1.88 \mathrm{~s}\right)$ by more than $50 \%$ because the Chi-Chi 


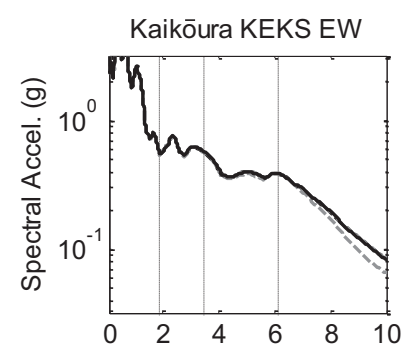

(a)

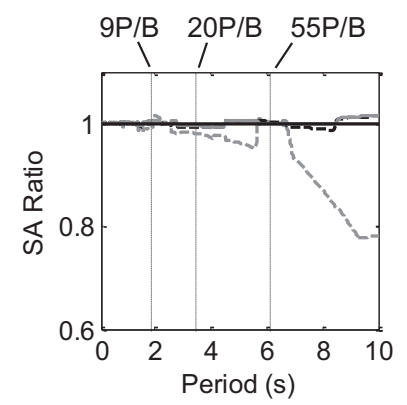

(d)

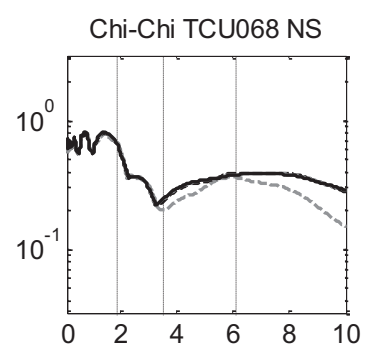

(b)

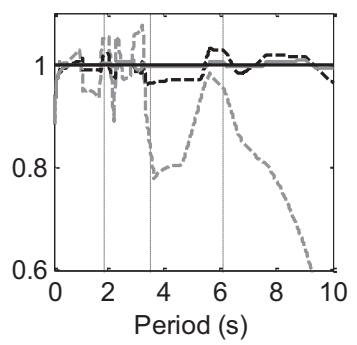

(e)

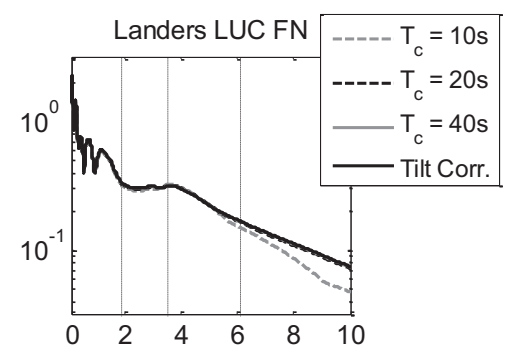

(c)

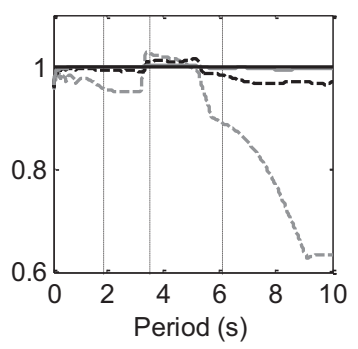

(f)

Figure 14. 5\%-damped response spectra of the (a) Kaiköura KEKS EW, (b) Chi-Chi TCU068 NS, and (c) Landers LUC FN records. The $T_{c}=10,20$, and $40 \mathrm{~s}$ records are compared with the tilt-corrected records. (d)-(f) To more easily compare spectra, the SA ratios (Equation 10) are plotted for the filtered records.

TCU068 NS record has significant long-period content. For the Landers LUC FN record, for the 20P model $\left(T_{1}=3.50 \mathrm{~s}\right)$, the NGA-West 2 record yields a collapse capacity $37 \%$ higher than the corresponding tilt-corrected record, despite the fact that the NGA-West2 record is not high-pass filtered. This discrepancy is caused by the removal of a sixth-order polynomial fit in the NGA-West 2 processing procedure.

Interestingly, for the considered records, demeaned raw records generally yield collapse capacities more similar to the tilt-corrected records than records filtered with $T_{c}<20 \mathrm{~s}$. This implies that applying high-pass filters with corner periods that are too low may remove so much of the true ground motion that one would be better off simply applying the raw ground motion record to a building model despite the presence of long-period noise. Of course, one can imagine a raw record whose signal is so distorted (e.g. $30^{\circ}$ of tilt) that structural analysis will yield non-physical results, but in the cases we analyzed in this study, calculated tilt was never more than $3^{\circ}$, and the results of structural analysis were rarely affected.

It should be noted that this study considered a relatively small set of building models and a finite number of ground motion records. Some of the important conclusions made here only applied to small number of the considered structural analyses, so it is possible that extrapolating these trends to hold for a wide variety of ground motions and structures may be spurious. However, it may also be the case that the conclusions of this study hold for an even higher proportion of ground motions than would be expected. Due to the small sample sizes, it is recommended that further work be done to develop statistically 
significant "rules" that can be followed in practice. Regardless, the fact that there exist ground motion records such as Chi-Chi TCU068 NS and Landers LUC FN that exhibit these aforementioned trends to a significant degree means it is important to be careful when selecting ground motions for structural analysis and to understand the potential limitations of using processed ground motion records.

Dependence of the results presented in this article on the as-recorded direction was informally investigated, but the findings were inconclusive and thus not included, for brevity. Further work is needed to clarify if the effects on structural response of ground motion processing may depend on the orientation of record with respect to the source. This may be of particular concern for pulse-like motions.

It appears particularly difficult to predict a priori when processing ground motions will change "severe hardening" behavior in IDA, which, as seen in the response of the 20P model to different versions of the Landers LUC FN record, can significantly affect the perceived collapse capacity of the structure. As such, it is recommended that further work be done to understand if it is possible to predict, to any degree, if severe hardening is likely to be observed in IDA for a given building model and ground motion. This study has demonstrated that if severe hardening is observed, then the collapse capacity of the structure could be very sensitive to small changes in the ground motion. This could also be true of, for example, small changes to modeling assumptions, which could have important implications for quantifying the effects of modeling uncertainty.

It is noted that recent guidelines for the performance-based design of tall buildings (e.g. TBI, 2017) suggest adding static offsets (or "fling-steps") to input ground motions that may have been removed during the NGA-West 2 processing procedures. Even though this procedure will result in a more realistic input ground motion, it may not completely undo the effects of the original high-pass filter, and these possible impacts may warrant further study.

\section{Acknowledgments}

The authors thank the anonymous reviewers, whose feedback greatly improved the quality of this paper. Any opinions, findings, and conclusions or recommendations expressed in this material are those of the authors and do not necessarily reflect the views of the National Science Foundation.

\section{Declaration of conflicting interests}

The author(s) declared no potential conflicts of interest with respect to the research, authorship, and/ or publication of this article.

\section{Funding}

The author(s) disclosed receipt of the following financial support for the research, authorship, and/ or publication of this article: This material is based upon work supported by the National Science Foundation Graduate Research Fellowship Program under Grant No. DGE-1144469.

\section{References}

AISC (2018) Prequalified connections for special and intermediate steel moment frames for seismic applications. Including Supplement No. 1, ANSI/AISC 358-16, ANSI/AISC 358s1-18. Chicago, IL: AISC. 
American Society of Civil Engineers (ASCE) (2016) Minimum design loads for buildings and other structures. ASCE/SEI 7-16. Reston, VA: ASCE.

Ancheta TD, Darragh RB, Stewart JP, Seyhan E, Silva WJ, Chiou BS-J, Wooddell KE, Graves JW, Kottke AR, Boore DM, Kishida T and Donahue JL (2014) NGA-West2 database. Earthquake Spectra 30: 989-1005.

Asano A and Tomotaka I (2016) Source rupture process of the foreshock and mainshock in the 2016 Kumamoto earthquake sequence estimated from kinematic waveform inversion of strong motion data. Earth, Planets and Space 78: 147.

Boore DM (2001) Effect of baseline corrections on displacements and response spectra for several recordings of the 1999 Chi-Chi, Taiwan, Earthquake. Bulletin of the Seismological Society of America 91: 1199-1211.

Boore DM (2005) On pads and filters: Processing strong-motion data. Bulletin of the Seismological Society of America 88: 745-750.

Boore DM and Akkar S (2003) Effect of causal and acausal filters on elastic and inelastic response spectra. Earthquake Engineering \& Structural Dynamics 32: 1729-1748.

Boore DM and Bommer JJ (2005) Processing of strong-motion accelerograms: Needs, options, and consequences. Soil Dynamics and Earthquake Engineering 25: 93-115.

Burks LS and Baker JW (2014) Fling in near-fault ground motions and its effect on structural collapse capacity. In: Proceedings, 10th U.S. national conference on earthquake engineering, Anchorage, AK, 21-25 July.

Buyco K (2018) Improving seismic collapse risk assessments of steel moment frame buildings. $\mathrm{PhD}$ Thesis, California Institute of Technology, Pasadena, CA.

Challa VRM and Hall JF (1994) Earthquake collapse analysis of steel frames. Earthquake Engineering \& Structural Dynamics 23: 1199-1218.

Chen X (1995) Near-field ground motion from the landers earthquake. PhD Thesis, California Institute of Technology, Pasadena, CA.

Dizon ABR (2016) A hybrid-parallel framework for the nonlinear seismic analysis of very tall buildings. $\mathrm{PhD}$ Thesis, California Institute of Technology, Pasadena, CA.

Ellsworth WL, Celebi M, Evans JR, Jensen EG, Kayen R, Metz MC, Nyman DJ, Roddick JW, Spudich P and Stephens CD (2004) Near-field ground motion of the 2002 Denali Fault, Alaska, earthquake recorded at Pump Station 10. Earthquake Spectra 20: 597-615.

Galetzka J, Melgar D, Genrich JF, Geng J, Owen S, Lindsey EO, Xu X, Bock Y, Avouac J-P, Adhikari LBNUB, Pratt-Sitaula B, Bhattarai TN, Sitaula BP, Moore A, Hudnut KW, Szeliga W, Normandeau J, Fend M, Flouzat M, Bollinger L, Shrestha P, Koirala B, Gautam U, Bhatterai M, Gupta R, Kandel T, Timsina C, Sapkota SN, Rajaure S and Maharjan N (2015) Slip pulse and resonance of the Kathmandu basin during the 2015 Gorkha earthquake, Nepal. Science 349: 1091-1095.

Graizer V (2006) Tilts in strong ground motion. Bulletin of the Seismological Society of America 96: 2090-2102.

Gupta A and Krawinkler H (1999) Seismic demands for performance evaluation of steel moment resisting frame structures. Technical Report 132. Stanford, CA: John A. Blume Earthquake Engineering Center, Stanford University.

Hall JF (1997) Seismic response of steel moment frame buildings to near-source ground motions. Technical Report 97-05. Pasadena, CA: Earthquake Engineering Research Laboratory, California Institute of Technology.

Hall JF (1998) Seismic response of steel moment frame buildings to near-source ground motions. Earthquake Engineering \& Structural Dynamics 27: 1445-1464.

Hall JF and Challa VRM (1995) Beam-column modeling. Journal of Engineering Mechanics 121: 1284-1291.

Hamling IJ, Hreinsdóttir S, Clark K, Elliott J, Liang C, Fielding E, Litchfield N, Villamor P, Wallace L, Wright TJD, 'Anastasio E, Bannister S, Burbidge D, Denys P, Gentle P, Howarth J, Mueller C, Palmer N, Pearson C, Power W, Barnes P, Barrell DJA, Van Dissen RR, Langridge Little T, Nicol A, Pettinga J, Rowland J and Stirling M (2017) Complex multifault rupture during the $2016 M_{W} 7.8$ Kaikoura earthquake, New Zealand. Science 349: 1091-1095. 
Haselton CB (2009) Evaluation of ground motion selection and modification methods: Predicting median interstory drift response of buildings. Technical Report PEER 2009/01. Berkeley, CA: Pacific Earthquake Engineering Research.

Ibarra LF, Medina RA and Krawinkler H (2005) Hysteretic models that incorporate strength and stiffness deterioration. Earthquake Engineering \& Structural Dynamics 34: 1489-1511.

Kamai R and Abrahamson N (2015) Are near-fault fling effects captured in the new NGA West2 ground motion models? Earthquake Spectra 31: 1629-1645.

Kohrangi M, Vamvatsikos D and Bazzurro P (2019) Pulse-like versus non-pulse-like ground motion records: Spectral shape comparisons and record selection strategies. Earthquake Engineering \& Structural Dynamics 48: 46-64.

Krishnan S and Muto M (2012) Mechanism of collapse of tall steel moment-frame buildings under earthquake excitation. Journal of Structural Engineering 138: 1361-1387.

Lu M, Li XJ, An XW and Zhao JX (2010) A preliminary study on the near-source strong-motion characteristics of the great 2008 Wenchuan Earthquake in China. Bulletin of the Seismological Society of America 100: 2491-2507.

Ma K-F, Lee C-T, Tsai Y-B, Shin T-C and Mori J (1999) The Chi-Chi, Taiwan earthquake: Large surface displacements on an inland thrust fault. EOS Transactions, American Geophysical Union 80: 605-620.

TBI (2017) Guidelines for performance-based seismic design of tall buildings, Version 2.03. Technical Report PEER 2017/06. Berkeley, CA: Pacific Earthquake Engineering Research Center.

Vamvatsikos D and Cornell CA (2002) Incremental dynamic analysis. Earthquake Engineering \& Structural Dynamics 31: 491-514.

Yamada M, Heaton TH and Beck J (2007) Real-time estimation of fault rupture extent using nearsource versus far-source classification. Bulletin of the Seismological Society of America 97: 1890-1910.

Yang J (2009) Nonlinear responses of high-rise buildings in giant subduction earthquakes. PhD Thesis, California Institute of Technology, Pasadena, CA. 